\title{
Research Square \\ Enhanced Ammonia Sensing By Cost-Effective ZnO Thin Films Through Yttrium Doping
}

\section{K. Ravichandran ( $\nabla$ kr1365@yahoo.com )}

AVVM Sri Pushpam College (Autonomous), Poondi, Thanjavur 613503, Tamil Nadu, India

\section{A. Jansi Santhosam}

AVVM Sri Pushpam College (Autonomous), Poondi, Thanjavur 613503, Tamil Nadu, India

\section{Aldossary Omar}

King Saud University

Mohd Ubaidhulla

King Saud University

\section{Research Article}

Keywords: Thin films, Yttrium doped ZnO, Nebulizer Spray Pyrolysis, NH3 sensor

Posted Date: June 12th, 2021

DOI: https://doi.org/10.21203/rs.3.rs-607950/v1

License: (9) This work is licensed under a Creative Commons Attribution 4.0 International License.

Read Full License 
Full Length Article

\title{
Enhanced ammonia sensing by cost-effective $\mathrm{ZnO}$ thin films through Yttrium doping
}

\author{
K. Ravichandran ${ }^{a, *}$ A. Jansi Santhosam ${ }^{a, b}$ Omar M. Aldossary ${ }^{c}$, Mohd Ubaidullah $^{d}$
}

${ }^{a}$ Materials Science Research Laboratory, PG and Research Department of Physics, AVVM Sri Pushpam College (Autonomous), (Affiliated to Bharathidasan University, Tiruchirappalli.) Poondi, Thanjavur-613 503, Tamil Nadu, India.

$b$ Research Department of Physics, Kunthavai Naachiyaar Govt. Arts College for Women (Autonomous), (Affiliated to Bharathidasan University, Tiruchirappalli.)Thanjavur - 613 007, Tamil Nadu, India.

${ }^{c}$ Department of Physics and Astronomy, College of Science, King Saud University, P.O. Box 2455, Riyadh 11451, Saudi Arabia.

${ }^{d}$ Department of Chemistry, College of Science, King Saud University, Riyadh 11451, Saudi Arabia.

\section{*Corresponding author:}

Dr. K. Ravichandran,

Associate Professor of Physics,

$P G$ and Research Department of Physics,

AVVM Sri Pushpam College (Autonomous),

Poondi, Thanjavur-613 503, Tamil Nadu, India.

E.mail:kkr1365@yahoo.com

kkravi1365@gmail.com 


\section{Graphical abstract}

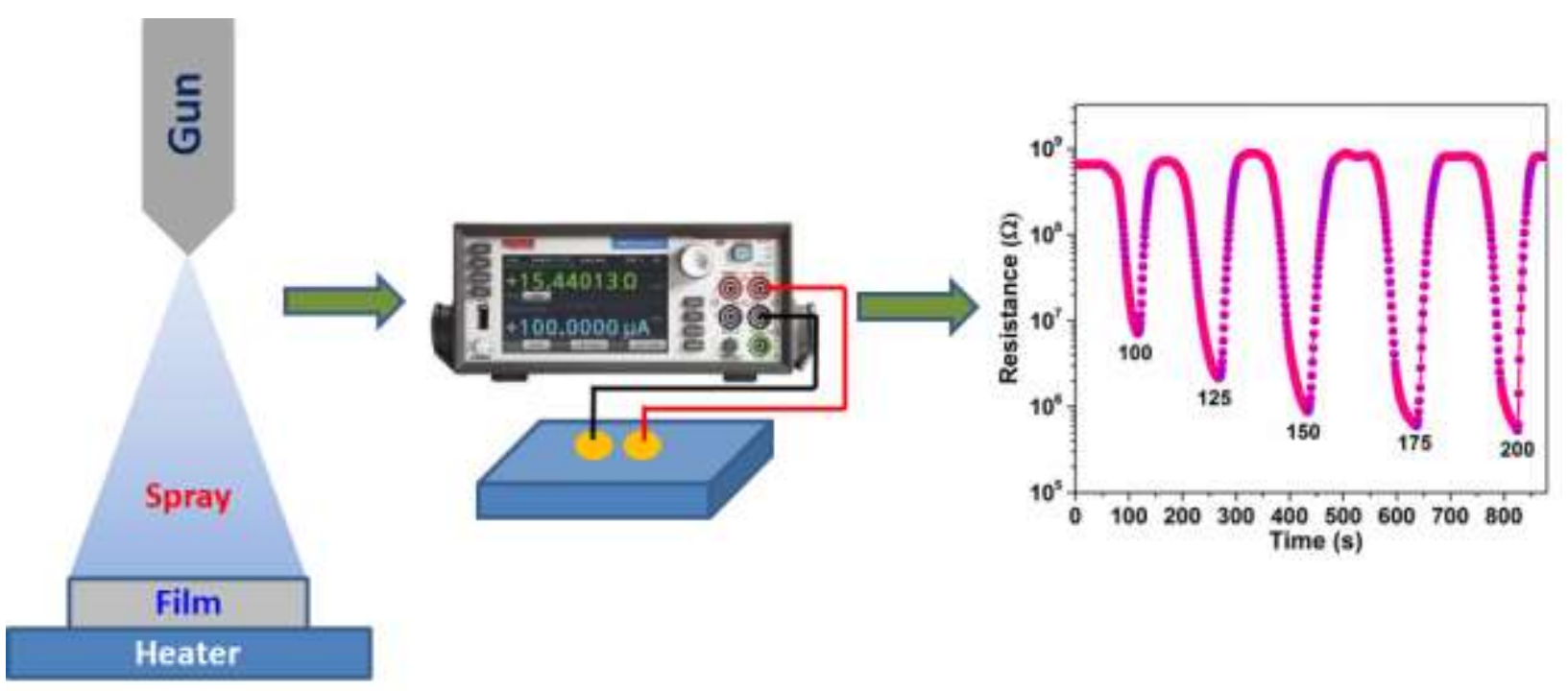

Nebulizer spray coated yttrium doped $\mathrm{ZnO}$ thin film for ammonia vapour sensing 


\section{Highlights}

Yttrium doped $\mathrm{ZnO}$ thin films have been fabricated for room temperature ammonia sensor

$>$ Surface roughness and oxygen vacancies are created by yttrium doping

Morphology and defect based gas sensing performance are explained

$>$ The maximum sensitivity observed for $5 \%$ yttrium doped $\mathrm{ZnO}$ film

$>$ The gas sensing mechanism yttrium doped $\mathrm{ZnO}$ film was proposed 


\title{
Enhanced ammonia sensing by cost-effective $\mathrm{ZnO}$ thin films through Yttrium doping
}

\begin{abstract}
Yttrium (Y) doped (doping concentration - 0, 1, 3 and $5 \mathrm{wt} \%$ ) $\mathrm{ZnO}$ thin films were deposited using spray pyrolysis technique. The structural, surface morphological, optical and compositional properties were analysed using X-Ray diffraction (XRD), Atomic Force Microscopy (AFM), UV-vis NIR spectrophotmetry (UV), photoluminescence study (PL) and elemental composition analysis. Ammonia vapour sensing properties such as response/recovery, stability and repeatability were studied at room temperature. XRD results confirmed that the prepared samples have hexagonal wurtzite structure. $\mathrm{ZnO}: \mathrm{Y}$ thin film with $5 \mathrm{wt} \%$ yttrium doping exhibits excellent sensing response of 99 , fast response/recovery times of $29 \mathrm{~s} / 7 \mathrm{~s}$ which may be due to the existence of oxygen vacancies in the case of $\mathrm{ZnO}: \mathrm{Y}(5 \mathrm{wt} \%)$ film sample confirmed by photoluminescence (PL) study. These oxygen vacancies attract more electrons and thus enhance the gas sensing. In addition, increase in the number of active sites caused by the substitution of $\mathrm{Y}^{3+}$ (trivalent) ions into the $\mathrm{Zn}^{2+}$ (divalent) regular sites as confirmed by the observed M-B (Moss-Burstein) effect also causes an enhancement in the gas sensing. Surface roughness, another reason for the enhanced sensitivity, has been confirmed by AFM.
\end{abstract}

Key words: Thin films, Yttrium doped ZnO, Nebulizer Spray Pyrolysis, $\mathrm{NH}_{3}$ sensor 


\section{Introduction}

Recent days, ammonia gas sensors play an important role in the industries of explosives, fertilizers, textiles and plastics [1]. The acceptable limit of ammonia for human body is $25 \mathrm{ppm}$, beyond which it can affect the various parts of the body causing damage to skin, eyes and respiratory tract [2]. Hence, researchers pay attention on making cost-effective ammonia sensors with improved ' $3 S$ ' parameters viz. sensitivity, stability and selectivity [3].

Plenty of metal oxide semiconductors like $\mathrm{V}_{2} \mathrm{O}_{5}, \mathrm{SnO}_{2}, \mathrm{TiO}_{2}, \mathrm{NiO}, \mathrm{BaTiO}_{3}$ and $\mathrm{ZnO}$ are widely used to detect ammonia vapours [4-10]. Of these, $\mathrm{ZnO}$ is one of the promising materials due to its attracting properties which include high thermal and chemical stability, non-toxicity, wide band gap, availability, environmentally benign nature, low-cost and ease of doping [11].

Moreover, literature survey shows that the gas sensing ability of $\mathrm{ZnO}$ can be improved through the addition of suitable dopants. Select dopants desirably alter the energy gap and surface morphology of the host material. In addition, doping causes an increase in defects and carrier concentration and thereby favouring the sensing phenomena [12]. Various rare earth metals like lanthanum, cerium, erbium, terbium, gadolinium and yttrium [13-18] have been used as dopants owing to their unique properties. Among the various rare earth elements,yttrium is used as dopant because of its peculiar properties arising from the $4 \mathrm{f}$ shell such as changes in energy band structure, morphology, surface to volume ratio and ability for creating more active centres at the grain boundaries [19, 20]. Thus, the gas sensing response of $\mathrm{ZnO}$ can be improved by the addition of suitable proportion of yttrium.

$\mathrm{Li}$ and co-workers reported that yttrium doped $\mathrm{ZnO}$ nanofibers exhibit good sensing to acetic acid [21] due to the large specific surface area and small grain size of $\mathrm{ZnO}: \mathrm{Y}$ nanofibers. Nithya et al. reported that yttrium doped titania nanoparticles prepared towards ethanol sensing exhibit short response/recovery times and long-term stability that may be due to the small crystal size 
and increase in oxygen vacancies [22]. Shruthi et al. reported that $\mathrm{Y}_{2} \mathrm{O}_{3}-\mathrm{In}_{2} \mathrm{O}_{3}$ nanocomposites exhibit sharp response/recovery times for methanol detection. It may be attributed to the formation of hetero junction between host and dopant materials [23]. However, to the best of our knowledge yttrium doped $\mathrm{ZnO}$ thin films towards ammonia sensing is scarcely available in the literature.

Undoped and doped $\mathrm{ZnO}$ films can be prepared by different techniques like magnetron sputtering, hydrothermal, sol gel, wet chemical route, SILAR and nebulizer spray Pyrolysis method [24-29]. Among these methods, nebulizer spray pyrolysis offers many advantages: economic, simple and safe, facilitate large surface area coating, flexible process parameters and uniform thickness [30].

In this work, undoped and yttrium doped $\mathrm{ZnO}$ film sensors have been developed using cost effective nebulizer spray pyrolysis method. The sensing ability, response and recovery times and stability of the sensor towards the reducing vapour $\left(\mathrm{NH}_{3}\right)$ at room temperature were studied and reported.

\section{Experimental details}

\subsection{Chemicals used}

Zinc acetate dihydrate $\left(\mathrm{Zn}\left(\mathrm{CH}_{3} \mathrm{COO}\right)_{2} \cdot 2 \mathrm{H}_{2} \mathrm{O}\right)$, yttrium nitrate hexahydrate $\left(\mathrm{Y}\left(\mathrm{NO}_{3}\right)_{3} \cdot 6 \mathrm{H}_{2} \mathrm{O}\right)$ were purchased from Sigma Aldrich and used without any further purification.

\subsection{Film deposition}

$\mathrm{Zn}\left(\mathrm{CH}_{3} \mathrm{COO}\right)_{2} \cdot 2 \mathrm{H}_{2} \mathrm{O}$ and $\mathrm{Y}\left(\mathrm{NO}_{3}\right)_{3} \cdot 6 \mathrm{H}_{2} \mathrm{O}$ were used as host and dopant precursors, respectively and methanol $(10 \mathrm{~mL})$ was used as solvent. Four sets of stock solutions $(0.2 \mathrm{M})$ were prepared with dopant concentrations $0,1,3$ and $5 \mathrm{wt} \%$. The solution was stirred for 15 minutes at $35^{\circ} \mathrm{C}$. Substrates (glass) were cleaned well with usual cleaning procedure and then 
placed on the substrate holder (hot plate) maintained at $450^{\circ} \mathrm{C}$. The solution was sprayed on the hot substrates over the area of $2.5 \times 7.5 \mathrm{~cm}^{2}$. The distance between the spray nozzle and substrate was optimized as $30 \mathrm{~mm}$. Nebulizer was mounted with the help of a stand and slowly moved in horizontal direction to cover large surface area. After the deposition, the hot plate was allowed to cool to room temperature.

\subsection{Characterization techniques}

The structural characterization of the prepared thin films was made using X-ray diffraction (Panalytical X'Pert PRO) using $\mathrm{Cu}-\mathrm{K}_{\alpha}$ radiation $(\lambda=0.1540 \mathrm{~nm})$. Stylus profilometer was used to measure the thickness of the prepared films. Atomic Force Microscope was used to analyse the surface topography of the samples. A UV-vis-near-IR spectrophotometer (Perkin Elmer Lamda35) was used to study the transmittance. Fluorescence spectrophotometer (Perkin Elmer LS55) was used to record the photoluminescence spectra at room temperature $\left(\lambda_{\mathrm{exc}}=325 \mathrm{~nm}\right)$. Keithley Meter model-2450 was used to study the room temperature $\left(32^{\circ} \mathrm{C}\right)$ ammonia sensing.

\subsection{Sensing study}

The gas sensing setup consists of a cylindrical chamber and a computer assisted Keithley electrometer (model- 2450). The prepared thin film was placed inside the chamber and to attain a baseline, the sample's resistance was measured under dry air. The ammonia taken in solution form was injected into the chamber with the help of microliter syringe. The introduction of $\mathrm{NH}_{3}$ vapour produces a marked change in the resistance of the sensor. The reduction in resistance confirms the n-type behaviour of the sensor towards reducing vapours like $\mathrm{NH}_{3}$. The change in resistance was observed using Keithley meter. The chamber is opened to air ambience when the resistance attained the saturation level. The resistance values were measured with respect to base line and recorded for different ammonia concentrations. 


\section{Results and discussion}

\subsection{XRD study}

Figure 1 shows the X-Ray diffraction patternsof pure and doped $\mathrm{ZnO}$ thin films with yttrium doping concentrations 1,3 and $5 \mathrm{wt} \%$. From the figure, we observed that all the peaks at different $2 \theta$ values match well with the JCPDS card no 36-1451 which confirms the wurtzite (hexagonal) structure of the $\mathrm{ZnO}$. The diffraction peaks are at the angles $31.82^{\circ}, 34.53^{\circ}, 36.25^{\circ}$, $47.66^{\circ}, 57.12^{\circ}, 63.20^{\circ}$ and $68.32^{\circ}$ correspond to the Miller indices (100), (002), (101), (102), (110), (103) and (112), respectively. No secondary peaks related to yttrium as well as no shift in XRD peaks were observed which may be due to the low doping concentration of yttrium. From Fig.1, it is clearly observed that the preferential growth of $\mathrm{ZnO}: \mathrm{Y}$ is along (002) plane. The intensity of this preferential orientation decreases as the yttrium doping level increases which may be due to the deterioration of crystallinity [31]. This reduction in intensity may be due to the possible movement of zinc atoms into interstitial sites from the regular zinc locations caused by the substitution of yttrium ions [32]. Scherrer's formula was applied for calculating the crystallite size (D),

$D=\frac{0.94 \lambda}{\beta \cos \theta}$

Dislocation density and lattice parameters can be calculated using the formula,

$\frac{1}{d^{2}}=\frac{4}{3} \frac{\left(h^{2}+k^{2}+h k\right)}{a^{2}}+\frac{l^{2}}{c^{2}}$

$\delta=\frac{1}{D^{2}}$

The calculated values of crystallite size are presented in Table 1 . We noticed that the crystallite size gradually decreases with the increase of yttrium doping level. This may be due to the incorporation of $\mathrm{Y}^{3+}(0.89 \AA)$ into $\mathrm{Zn}^{2+}(0.74 \AA)$ site which causes deformation in the lattice system. This deformation in turn can lead to the restriction of growth of crystallite boundaries 
called Zener pinning effect [33]. Rietveld refinement analysis was performed using Bruker Topas version 6 to study the lattice parameters. From Table 1, it can be seen that there is a slight change in the lattice parameter values after doping which may be attributed to the difference in the ionic radii of zinc and yttrium ions. The observed increase in the value of dislocation density with the increase in doping concentration of yttrium shows the formation of defects on the surface of the film [34]. Reduction in the size of the crystallites and the increase in the defects will help for adsorbing more ammonia molecules [35].

\subsection{Surface morphological study}

Figure 2 shows the AFM images of the pure and yttrium (1, 3 and $5 \mathrm{wt} \%)$ doped $\mathrm{ZnO}$ films. From the figure, we can observe clear edges of the grains which are generally highly reactive when exposed to target gases. This is one of the main advantages in gas sensing applications [36]. The undoped $\mathrm{ZnO}$ thin film exhibits relatively low surface roughness, whereas, considerably higher roughness is observed when yttrium is incorporated into $\mathrm{ZnO}$ lattice. The roughness value for pure $\mathrm{ZnO}$ increases from 26 to $46 \mathrm{~nm}$ due to the influence of yttrium doping. This increase in roughness results in more active centres for gas adsorption favouring better sensing as explained by Wenzel's effect [37, 38]. EDX was used to identify the presence of elements in the prepared films. Figure $3 a$ and $b$ shows the EDX spectra which confirms the existence of zinc, oxygen and yttrium in the samples.

\subsection{Photoluminescence study}

In order to analyse the surface defects, photoluminescence (PL) study was used. Fig. 4 shows the PL spectra and its Lorentz fitting of pure and yttrium doped $\mathrm{ZnO}$ films. The emission band observed at $384 \mathrm{~nm}$ is related to the transition between the $\mathrm{CB}$ and VB [39]. This peak is found to shift to lower wavelength side due to the influence of yttrium doping. The blue-green emission peaks observed at $435 \mathrm{~nm}(2.84 \mathrm{eV})$ and $488 \mathrm{~nm}(2.53 \mathrm{eV})$ correspond to $\mathrm{Zn}_{\mathrm{i}}$ (zinc 
interstitials) and singly ionized $\mathrm{V}_{\mathrm{o}}$ (oxygen vacancies) as reported by Kumar et al. [40] and Radhidevi et al. [34]. Thus, the PL study confirms that the electron donor defect concentration increases when yttrium doping concentration is increased, which is favourable for gas sensing as it can be able to attract more number of gas molecules. In our case, the peaks shifted slightly towards the higher wavelength may be attributed to the bond length of Y-O (2.3 $⿱$ $)$ is relatively higher than $\mathrm{Zn}-\mathrm{O}(1.89 \AA)$. Therefore, the origin of the emission defects could be varied with respect to metal doping.

\subsection{Optical study}

Figure 5 shows the extrapolation of the leading edges of the plot to the $\mathrm{x}$-axis giving the energy band gap as per the Tauc's relation,

$(\alpha h v)^{2}=A\left(h v-E_{g}\right)$

From the figure, we can observe a slight increase in the energy gap as the yttrium doping concentration increases. This increase in the band gap may be due to the uplift in electron number caused by the $\mathrm{Y}^{3+}$ (trivalent) ions incorporation into the $\mathrm{ZnO}$ lattice. When, we dope yttrium with $\mathrm{ZnO}$, the Fermi level moves towards the conduction band of $\mathrm{ZnO}$ resulting in band gap widening as explained by Moss-Burstein effect [41].

\subsection{Sensing characteristics}

\subsubsection{Selectivity}

The sensing response of the prepared sample ( $\mathrm{ZnO}: \mathrm{Y}-5 \mathrm{wt} \%)$ tested towards six reducing vapours under room temperature is shown in Fig. 6. The selectivity study was carried out by keeping the concentration at $100 \mathrm{ppm}$ and the response was calculated using the formula,

$$
S=\frac{R_{a}}{R_{g}}
$$


The response valuesof the films are 4, 7, 10, 16, 22 and 99 for toluene, acetone, isopropanal, ethanol, methanol and ammonia. From the results, we observed that the film shows poor response to toluene, acetone, isopropanol, ethanol, methanol compared to ammonia. The reason for the best response to ammonia may be the electron donating ability of ammonia compared to other tested vapours due to the presence of lone pair of electrons [42].

\subsubsection{Sensing characteristics}

Figure 7 shows the response and recovery curves of pure and yttrium doped $\mathrm{ZnO}$ films exposed to $\mathrm{NH}_{3}$ vapours $(100 \mathrm{ppm})$ at $32^{\circ} \mathrm{C}$. When yttrium doped $\mathrm{ZnO}$ thin films were exposed to $\mathrm{NH}_{3}$ vapour, a rapid change in resistance was observed indicating the response at room temperature. The response values of the films are 22, 39, 52 and 99 for undoped and yttrium (1, 3 and $5 \mathrm{wt} \%$ ) doped $\mathrm{ZnO}$ films, respectively. The corresponding response and recovery times are $52 \mathrm{~s} / 11 \mathrm{~s}, 39 \mathrm{~s} / 9 \mathrm{~s}, 30 \mathrm{~s} / 11 \mathrm{~s}$ and $29 \mathrm{~s} / 7 \mathrm{~s}$. Response and recovery times are the time to reach $90 \%$ decrease from the base line upon exposure of target gas and the time taken to return back to the base line, respectively. The results show that $5 \mathrm{wt} \%$ yttrium doped $\mathrm{ZnO}$ film exhibits quick response and recovery times compared to other films. To study further, transient resistance response curves for $5 \mathrm{wt} \%$ yttrium doped $\mathrm{ZnO}$ films towards different concentrations of $\mathrm{NH}_{3}$ vapours (from 100-200 ppm) were recorded (Fig.8). From the figure, we found the same fashion of reduction in resistance during the application of $\mathrm{NH}_{3}$ and increase in resistance as the consequence of removal of $\mathrm{NH}_{3}$ vapour for all the five cases. This decreasing and increasing nature of the resistance of n-type material shows the stability of the sensor.

Results of recent research works on $\mathrm{NH}_{3}$ sensing at room temperature are presented in Table 2. Pandeeswari et al. reported that $\beta-\mathrm{Ga}_{2} \mathrm{O}_{3}$ film exhibits excellent sensing towards $\mathrm{NH}_{3}$ and fast response/recovery times of $40 \mathrm{~s} / 18 \mathrm{~s}$. This rapid response may be due to the catalytic action of $\beta-\mathrm{Ga}_{2} \mathrm{O}_{3}$ [42]. Niu et al. reported that $\mathrm{P}_{2} \mathrm{O}_{5}$ catalyzed covalent triazine frameworks 
exhibit short response/recovery times of 54 s/200 s. It may be attributed to the transfer of electrons between triazine ring and $\mathrm{NH}_{3}$ molecules [43]. According to Yan et al., $\mathrm{Ag}_{3} \mathrm{PO}_{4}$ nanoparticles exhibit superior sensing activity towards $\mathrm{NH}_{3}$. The reason may be the lone pair of $\mathrm{NH}_{3}$ molecules that coordinate with the atoms of $\mathrm{Ag}_{3} \mathrm{PO}_{4}$, resulting in a large adsorption of energy and electron transferring [44]. Kathwate et al. reported that $\mathrm{Al}$ doped $\mathrm{ZnO}$ thin films exhibit fast response/recovery times of $29 \mathrm{~s} / 19 \mathrm{~s}$ that might be attributed to the structural and morphological changes occurred due to $\mathrm{Al}$ doping [45]. In the present work, yttrium doped $\mathrm{ZnO}$ thin films exhibit short response/recovery times of $29 \mathrm{~s} / 7 \mathrm{~s}$ towards $\mathrm{NH}_{3}$ vapours.

\subsubsection{Repeatability and stability}

Repeatability, one of the important factors in sensing, was tested for 5 wt $\%$ yttrium doped $\mathrm{ZnO}$ film sensor for five cycles of $\mathrm{NH}_{3}(100 \mathrm{ppm})$. We found that the response of the sensor remains the same for all the five cycles as shown in Fig. (9a) indicating that the prepared $\mathrm{ZnO}$ :Y film (with $5 \mathrm{wt} \%$ doping) is a good sensing material for sensing $\mathrm{NH}_{3}$ vapours.

The stability of the sensor is another essential parameter in vapour sensing. To determine the stability, $5 \mathrm{wt} \%$ yttrium doped $\mathrm{ZnO}$ sensor was tested after 50 days of its preparation with $\mathrm{NH}_{3}$ vapours $(100 \mathrm{ppm})$ at $32^{\circ} \mathrm{C}$. Figure $9 \mathrm{~b}$ shows that the response of the sensor is nearly the same even after 50 days.

\subsubsection{Sensing mechanism}

Gas sensing is a surface controlled reactionin which change in resistance of the sensor might be attributed to the adsorption and desorption of target vapours (Fig.10). The adsorbed oxygen molecules can form three types of ions $\left(\mathrm{O}_{2}^{-}\right.$-below $100^{\circ} \mathrm{C}($ equation 6$), \mathrm{O}^{-}$-between $100^{\circ} \mathrm{C}$ to $300^{\circ} \mathrm{C}$ and $\mathrm{O}^{2-}$-above $300^{\circ} \mathrm{C}$ ). Previous reports showed the formation of $\mathrm{O}_{2}^{-}$ions on the film surface at room temperature [40]. In the present study, we believe that these oxygen ions 
form a depletion layer over the surface of $\mathrm{ZnO}: \mathrm{Y}$ films and thus resulting in a high electrical resistance.

$\mathrm{O}_{2}+\mathrm{e}^{-}=\mathrm{O}_{2}^{-}{ }^{-}$(ads)

Upon exposure to $\mathrm{NH}_{3}$ vapours, desorption takes place and concomitantly electrons already trapped are released back to the film which results in reduction in resistance as per the equation (7). As $\mathrm{ZnO}$ is an n-type material having a wide band gap, large number of oxygen ions are adsorbed on the $\mathrm{ZnO}: \mathrm{Y}$ film surface. Oxygen vacancies and zinc interstitials are donor defects favouring the adsorption of oxygen ions and consequently increase the interaction of $\mathrm{NH}_{3}$ molecules with the sensing surface. The higher the donor defects the higher is the adsorption of oxygen molecules which leads to an increase in the sensing response as evidenced from the PL results.

$4 \mathrm{NH}_{3}+\mathrm{O}_{2}^{-}{ }_{(\mathrm{ads})}^{-}=2 \mathrm{~N}_{2}+6 \mathrm{H}_{2} \mathrm{O}+3 \mathrm{e}^{-}$

\section{Conclusion}

Yttrium doped $\mathrm{ZnO}$ films prepared using cost-effective spray pyrolysis technique exhibit good ammonia vapour sensing. The $\mathrm{ZnO}$ sensor with $5 \mathrm{wt} \%$ yttrium doping shows superior sensing response (99) and quick response/recovery times of $29 \mathrm{~s} / 7 \mathrm{~s}$ for $100 \mathrm{ppm}$ of ammonia at $32^{\circ} \mathrm{C} . \mathrm{ZnO}: \mathrm{Y}(5 \mathrm{wt} \%)$ film has more oxygen vacancies and zinc interstitials, which can adsorb more ammonia molecules during sensing. The enhanced sensing response may also be due to the excessive electrons donated by the trivalent (yttrium) ion into the divalent (zinc) lattice. The resultant band gap widening is evidenced by the Moss-Burstein effect. Increase in roughness plays a crucial role in sensing. From the above results, we have concluded that yttrium doped $\mathrm{ZnO}$ thin films can be considered as promising candidates for $\mathrm{NH}_{3}$ sensing.

\section{Acknowledgement}


The authors from KSU extend their appreciation for funding part of the work to the Researchers Supporting Project number (RSP-2020/61), King Saud University, Riyadh, Saudi Arabia.

\section{Conflict of interests}

The authors declare that they have no conflict of interest.

\section{References}

[1] E. Hemalatha, N. Gopalakrishnan, Synthesis and characterization of pure and $\mathrm{Cd}$ doped $\mathrm{ZrO}_{2}$ nanostructures for ammonia sensing application, Mater. Today., https://doi.org/10.1016/j.matpr.2020.06.197

[2] Roto Rotoa, Aditya Rianjanu, Innas Amaliya Fatyadi, Ahmad Kusumaatmaja, Kuwat Triyana, Enhanced sensitivity and selectivity of ammonia sensing by QCM modified with boric acid-doped PVAc nanofiber, Sens. Actuator A Phys., 304 (2020) 111902

[3] Susmita Kundu, Amit Kumar, Low concentration ammonia sensing performance of Pd incorporated indium tin oxide, J Alloy Compd.,750 (2019) 245-255

[4] Shobha N. Birajdar, Neha Y. Hebalkar, Satish K. Pardeshi, Sulabha K. Kulkarni, Parag V. Adhyapak, Ruthenium-decorated vanadium pentoxide for room temperature ammonia sensing, RSC Adv., 9 (2019) 28735

[5] S. Maheswari, M. Karunakaran, K. Kasirajan, Nebuliser spray pyrolysis coated undoped and Tb-doped $\mathrm{SnO}_{2}$ thin films: Ammonia vapour sensor application, Sustainable Humanosphere, ISSN: 1880 - 6503 (2020) Volume: 16 Issue: 1

[6] Z.P. Tshabalala, K. Shingange, F.R. Cummings, O.M. Ntwaeaborwa, G.H. Mhlongo, D.E. Motaung, Ultra-Sensitive and Selective $\mathrm{NH}_{3}$ Room Temperature Gas Sensing Induced by Manganese-doped Titanium Dioxide Nanoparticles, J. Colloid Interface Sci., 504 (2017) 371386

[7] Xiaolan Deng, Lilan Zhang, Jing Guo, Qinjun Chen, Jianmin Ma, ZnO enhanced NiO-based gas sensors towards ethanol, Mater. Res. Bull., 90 (2017) 170-174

[8] Xuesong Wang, Jinbao Zhang, Lianyuan Wang, Shouchun Li, Li Liu, Chang Su, Lili Liu, High Response Gas Sensors for Formaldehyde Based on Er-Doped $\operatorname{In}_{2} \mathrm{O}_{3}$ Nanotubes, J Mater Sci Technol., 31 (2015) 1175-1180

[9] R.P. Patil, Chaitanya Hiragond, G.H. Jain, Pawan K. Khanna, V.B. Gaikwad, Priyesh V. More, La doped $\mathrm{BaTiO}_{3}$ nanostructures for room temperature sensing of $\mathrm{NO}_{2} / \mathrm{NH}_{3}$ : Focus on $\mathrm{La}$ concentration and sensing mechanism, Vacuum., 166 (2019) 37-44

[10] R. Sankar Ganesh, E. Durgadevi, M. Navaneethan, V.L. Patil, S. Ponnusamy, C. Muthamizhchelvan, S. Kawasaki, P.S. Patil, Y. Hayakawa, Controlled synthesis of Ni-doped $\mathrm{ZnO}$ hexagonal microdiscs and their gas sensing properties at low temperature, Chem. Phys. Lett., 689(2017) 92-99

[11] A. Manivasaham, K. Ravichandran, K. Subha: Light intensity effects on the sensitivity of ZnO:Cr gas sensor, Surf. Eng., 33 (2017) Issue 11

[12] V.L. Patil, S.A. Vanalakar, N.L. Tarwal, A.P. Patil, T.D. Dongale, J.H. Kim, P.S. Patil, Construction of $\mathrm{Cu}$ doped $\mathrm{ZnO}$ nanorods by chemical method for Low temperature detection of $\mathrm{NO}_{2}$ gas, Sens. Actuator A Phys., 299 (2019) 111611

[13] A. Jansi Santhosam, K. Ravichandran, Mohd. Shkir, M. Sridharan, Effect of La incorporation on the $\mathrm{NH}_{3}$ sensing behaviour of $\mathrm{ZnO}$ thin films prepared using low-cost nebulizer spray technique, J. Mater. Sci.: Mater. Electron., 31 (2020) 13240-13248 
[14] M. Rajendra Prasad, M. Haris, M. Sridharan, $\mathrm{NH}_{3}$ sensing properties of surface modified Ce-doped nanostructured $\mathrm{ZnO}$ thin films prepared by spray pyrolysis method, Sens. Actuator A Phys., 269 (2018) 435-443

[15] Singh G, Virpal, Singh RC, Highly sensitive gas sensor based on Er-doped $\mathrm{SnO}_{2}$ nanostructures and its temperature dependent selectivity towards hydrogen and ethanol, Sensor Actuat B-Chem., 282 (2019) 373-383

[16] Anita Hastir, Nipin Kohli, Ravi Chand Singh, Temperature dependent selective and sensitive terbium doped $\mathrm{ZnO}$ nanostructures, Sensor Actuat B-Chem., 231 (2016) 110-119

[17] V. Anand, A. Sakthivelu, K. Deva Arun Kumar, S. Valanarasu, V. Ganesh, Mohd. Shkir, A. Kathalingam, S. AlFaify, Novel rare earth $\mathrm{Gd}$ and $\mathrm{Al}$ co-doped $\mathrm{ZnO}$ thin films prepared by nebulizer spray method for optoelectronic applications, Super lattice Microst., 123 (2018) 311322

[18]Narinder Kaur, Sanjeev K. Sharma, Deuk Young Kim, Narinder Singh, Physica B Condens. Matter., 500 (2016) 179-185

[19] K. Deva Arun Kumar, S. Valanarasu, Joice Sophia Ponraj, Brian Jeevan Fernandes, M. Shkir, S. AlFaify, Prashantha Murahari, K. Ramesh, Effect of Er doping on the ammonia sensing properties of $\mathrm{ZnO}$ thin films prepared by a nebulizer spray technique, J. Phys. Chem. Solids., 144 (2020) 109513

[20] Haiyu Qin, Jing Xie, Hui Xu, Yizhao Li, Yali Cao, Green solid-state chemical synthesis and excellent xylene detecting behaviors of Y-doped- $\mathrm{MoO}_{3}$ nanoarrays, Mater Res Bull., 93 (2017) 256-263

[21] X.B. Li, Q.Q. Zhang, S.Y. Ma, G.X. Wan, F.M. Li, X.L. Xu, Microstructure optimization and gas sensing improvement of $\mathrm{ZnO}$ spherical structure through yttrium doping, Sensor Actuat B-Chem., 195 (2014) 526-533

[22] N. Nithya, G. Bhoopathi, G. Magesh, O.N. Balasundaram, Synthesis and characterization of yttrium doped titania nanoparticles for gas sensing activity, Mater. Sci. Semicond. Process., 99 (2019) 14-22

[23] Julakanti Shruthi, Nagabandi Jayababu, P. Ghosal, M.V. Ramana Reddy, Ultrasensitive sensor based on $\mathrm{Y}_{2} \mathrm{O}_{3}-\mathrm{In}_{2} \mathrm{O}_{3}$ nanocomposites for the detection of methanol at room temperature, Ceram. Int., 45 (2019) 21497-21504

[24] Veena Mounasamy, Ganesh Kumar Mani, Dhivya Ponnusamy, Kazuyoshi Tsuchiya, Arun K. Prasad, Sridharan Madanagurusamy, Sub-ppm level detection of tri-methylamine using $\mathrm{V}_{2} \mathrm{O}_{3}-$ $\mathrm{Cu}_{2} \mathrm{O}$ mixed oxide thin films, Ceram.Int., 45 (2019) 19528-19533

[25] R.Sankar Ganesh, E.Durgadevi, M.Navaneethan, V.L.Patil, S.Ponnusamy, C.Muthamizhchelvan, S.Kawasaki, P.S.Patil, Y.Hayakawa, Tuning the selectivity of $\mathrm{NH}_{3}$ gas sensing response using Cu-doped $\mathrm{ZnO}$ nanostructures, Sens. Actuator A Phys., 269 (2018) 331341

[26]Poloju, M, Jayababu. N, Ramana Reddy M. V., Improved gas sensing performance of Al doped $\mathrm{ZnO} / \mathrm{CuO}$ nanocomposite based ammonia gas sensor, MSEB., 227 (2017) 61-67

[27]Salvatore Gianluca Leonardi , Wojtek Wlodarski , Yongxiang Li, Nicola Donato, Anna Bonavita , Giovanni Neri, Ammonia sensing properties of two-dimensional tin disulphide/tin oxides $\left(\mathrm{SnS}_{2} / \mathrm{SnO}_{2-\mathrm{x}}\right)$ mixed phases, J Alloy Compd., 781 (2019) 440-449

[28] K.Radhi Devi, G. Selvan, M. Karunakaran, K. Kasirajan, Mohd. Shkir, S. Alfaify,A SILAR fabrication of nanostructured $\mathrm{ZnO}$ thin films and their characterizations for gas sensing applications: An effect of Ag concentration, Super lattice Microst., 143 (2020) 106547

[29] V.Gopala Krishnan, P.Elango, Influence of $\mathrm{Ba}$ doping concentration on the physical properties and gas sensing performance of $\mathrm{ZnO}$ nanocrystalline films: Automated nebulizer spray pyrolysis (ANSP) method, Optik., 141 (2017) 83-89 
[30] K. Ravichandran, K. Subha, N. Dineshbabu, A. Manivasaham, Enhancing the electrical parameters of $\mathrm{ZnO}$ films deposited using a low-cost chemical spray technique through $\mathrm{Ta}$ doping, J Alloy Compd., 656 (2016) 332-338

[31] K. Karthika, K. Ravichandran, Tuning the Microstructural and Magnetic Properties of ZnO Nanopowders Through the Simultaneous Doping of Mn and Ni for Biomedical Applications, J Mater Sci Technol., 31(2015) 1111-1117

[32]K. Karthika, K.Ravichandran, Enhancing the magnetic and antibacterial properties of $\mathrm{ZnO}$ nanopowders through Mn+Co doping, Ceram.Int., 41 (2015) 7944-7951

[33]K. Ravichandran, A. Manivasaham, Enhanced ammonia sensing by $\mathrm{Sn}$ doped $\mathrm{ZnO}$ films prepared by a low-cost fully automated nebulizer spray technique, J Mater Sci: Mater Electron., 28 (2017) 6335-6344

[34] K. Radhi Devi, G. Selvan , M. Karunakaran , I. Loyola Poul Raj , V. Ganesh, S. AlFaify, Enhanced room temperature ammonia gas sensing properties of strontium doped $\mathrm{ZnO}$ thin films by cost-effective SILAR method, Mater. Sci. Semicond. Process., 119 (2020) 105117

[35] Rekha Pilliadugula, N. Gopala Krishnan, Effect of pH dependent morphology on room temperature $\mathrm{NH}_{3}$ sensing performances of $\beta-\mathrm{Ga}_{2} \mathrm{O}_{3}$, Mater. Sci. Semicond. Process., 112 (2020) 105007

[36] Veena Mounasamy, Ganesh Kumar Mani, Dhivya Ponnusamy, Kazuyoshi Tsuchiya, Arun K. Prasad, Sridharan Madanagurusamy, Network mixed metal oxide $\left(\mathrm{V}^{4+}\right.$ and $\left.\mathrm{Ti}^{4+}\right)$ nanostructures as potential material for the detection of tri-methylamine, New J. Chem., 43 (2019) 11069

[37] Veena Mounasamy, Ganesh Kumar Mani, Dhivya Ponnusamy, Kazuyoshi Tsuchiya, Arun K. Prasad, Sridharan Madanagurusamy, Template-free synthesis of vanadium sesquioxide $\left(\mathrm{V}_{2} \mathrm{O}_{3}\right)$ nanosheets and their room-temperature sensing performance, J. Mater. Chem.A., 6 (2018) 6402

[38] Yaoyu Yin, Yanbai Shen, Pengfei Zhou, Rui Lu, Ang Li, Sikai Zhao, Wengang Liu, Dezhou Wei, Kefeng Wei, Fabrication, characterization and n-propanol sensing properties of perovskite-type $\mathrm{ZnSnO}_{3}$ nanospheres based gas sensor, Appl Surf Sci., 509 (2020) 145335

[39] K. Ravichandran, K. Shantha Seelan, P. Kavitha, S. Sriram, Influence of $\mathrm{Cu}+\mathrm{g}-\mathrm{C}_{3} \mathrm{~N}_{4}$ incorporation on the photocatalytic dye decomposition of $\mathrm{ZnO}$ film coated on stainless steel wire meshes, J Mater Sci: Mater Electron., 30 (2019) 19703-19717

[40] A. Jansi Santhosam, K. Ravichandran, Tansir Ahamad, Sens.Actuator A Phys., 316 (2020) 112376

[41] Weiwei Guo, Tianmo Liu, Rong Sun, Yong Chen, Wen Zeng, Zhongchang Wang, Hollow, porous, and yttrium functionalized $\mathrm{ZnO}$ nanospheres with enhanced gas-sensing performances, Sensor Actuat B-Chem., 178 (2013) 53- 62

[42] R. Pandeeswari, B.G. Jeyaprakash, High sensing response of $\beta-\mathrm{Ga}_{2} \mathrm{O}_{3}$ thin film towards ammonia vapours: Influencing factors at room temperature, Sensor Actuat B-Chem., 195 (2014) 206-214

[43] Fang Niu, Zhen-Wu Shao, Li-Ming Tao, Yong Ding, Covalent triazine-based frameworks for $\mathrm{NH}_{3}$ gas sensing at room temperature, Sensor Actuat B-Chem., 321 (2020) 128513

[44] Fanfan Yan, Guowen Shen, Xi Yang, Tianjiao Qi, Jie Sun, Xinghua Li, Mingtao Zhang, Low operating temperature and highly selective $\mathrm{NH}_{3}$ chemi-resistive gas sensors based on $\mathrm{Ag}_{3} \mathrm{PO}_{4}$ semiconductor, Appl Surf Sci., 479 (2019) 1141-1147

[45] L.H. Kathwate, G. Umadevi, P.M. Kulal, P. Nagaraju, D.P. Duba, A.K. Nanjundan, V.D. Mote, Ammonia Gas sensing properties of Al doped $\mathrm{ZnO}$ thin films, Sens. Actuator A Phys., 313 (2020) 112193

[46] Ali Akbar, Mausumi Das, D. Sarkar, Room temperature ammonia sensing by CdS nanoparticle decorated polyaniline (PANI) nanorods, Sens. Actuator A Phys., 310 (2020) 112071 
[47] Wang W, Zhen Y, Zhang J, Li Y, Zhong H, Jia Z, Xiong Y, XueQ,Yan Y, Alharbib NS, Hayat $\mathrm{T}, \mathrm{SnO}_{2}$ nanoparticles-modified 3D-multilayer $\mathrm{MoS}_{2}$ nanosheets for ammonia gas sensing at room temperature, Sensor Actuat B-Chem., 321(2020) 128471

[48] Yuli Zhou, Jian Wang, Xinkang Li, Flexible room-temperature gas sensor based on poly (para-phenyleneterephthalamide) fibers substrate coupled with composite $\mathrm{NiO} @ \mathrm{CuO}$ sensing materials for ammonia detection, Ceram. Int., 46 (2020) 13827-13834

[49] P.G.Su, L.Y.Yang, $\mathrm{NH}_{3}$ gas sensor based on $\mathrm{Pd} / \mathrm{SnO}_{2} / \mathrm{RGO}$ ternary composite operated at room-temperature, Sens. Actuators B Chem., 223 (2016) 202-208 


\section{Figure Captions}

Fig.1 X-ray diffraction patterns of $\mathrm{ZnO}$ and $\mathrm{ZnO}: \mathrm{Y}$ thin films

Fig.2 AFM images of ZnO:Y thin films with different $Y$ loading levels a) 0 b) 1 c) 3 and d) $5 \mathrm{wt} \%$

Fig.3 (a,b) EDX spectra of $\mathrm{ZnO}$ and $\mathrm{ZnO}: \mathrm{Tb}(5 \mathrm{wt} \%)$ thin films

Fig.4 Photoluminescence spectra of $\mathrm{ZnO}$ and $\mathrm{Y}$ doped $\mathrm{ZnO}$ thin films

Fig.5 Tauc's plot of $\mathrm{ZnO}$ and $\mathrm{ZnO}: \mathrm{Y}(1,3$ and $5 \mathrm{wt} \%)$ thin films to measure the bandgap

Fig.6 Selectivity of $\mathrm{ZnO}: \mathrm{Y}-5 \mathrm{wt} \%$ thin film towards various test vapours

Fig.7 Response and recovery curves of $\mathrm{ZnO}: \mathrm{Y}(0,1,3$ and $5 \mathrm{wt} \%)$ thin films towards $100 \mathrm{ppm}$ of $\mathrm{NH}_{3}$ at room temperature

Fig.8 Response and recovery curves of $5 \mathrm{wt} \%$ yttrium doped $\mathrm{ZnO}$ thin film towards various concentrations of $\mathrm{NH}_{3}$

Fig.9.a) Repeatability curve of $5 \mathrm{wt} \%$ yttrium doped $\mathrm{ZnO}$ thin films b) Stability curve of $\mathrm{ZnO}: \mathrm{Y}$ $(0,1,3$ and $5 \mathrm{wt} \%)$ thin films over 50 days

Fig.10 Sensing mechanism of $\mathrm{ZnO}: \mathrm{Y}$ thin film

\section{Table Captions}

Table 1 Crystallite size, Lattice parameters and dislocation density of $\mathrm{ZnO}: \mathrm{Y}(0,1,3$ and 5 wt\%) thin films

Table 2 Response/recovery times and sensitivity of various materials towards $\mathrm{NH}_{3}$ sensing 


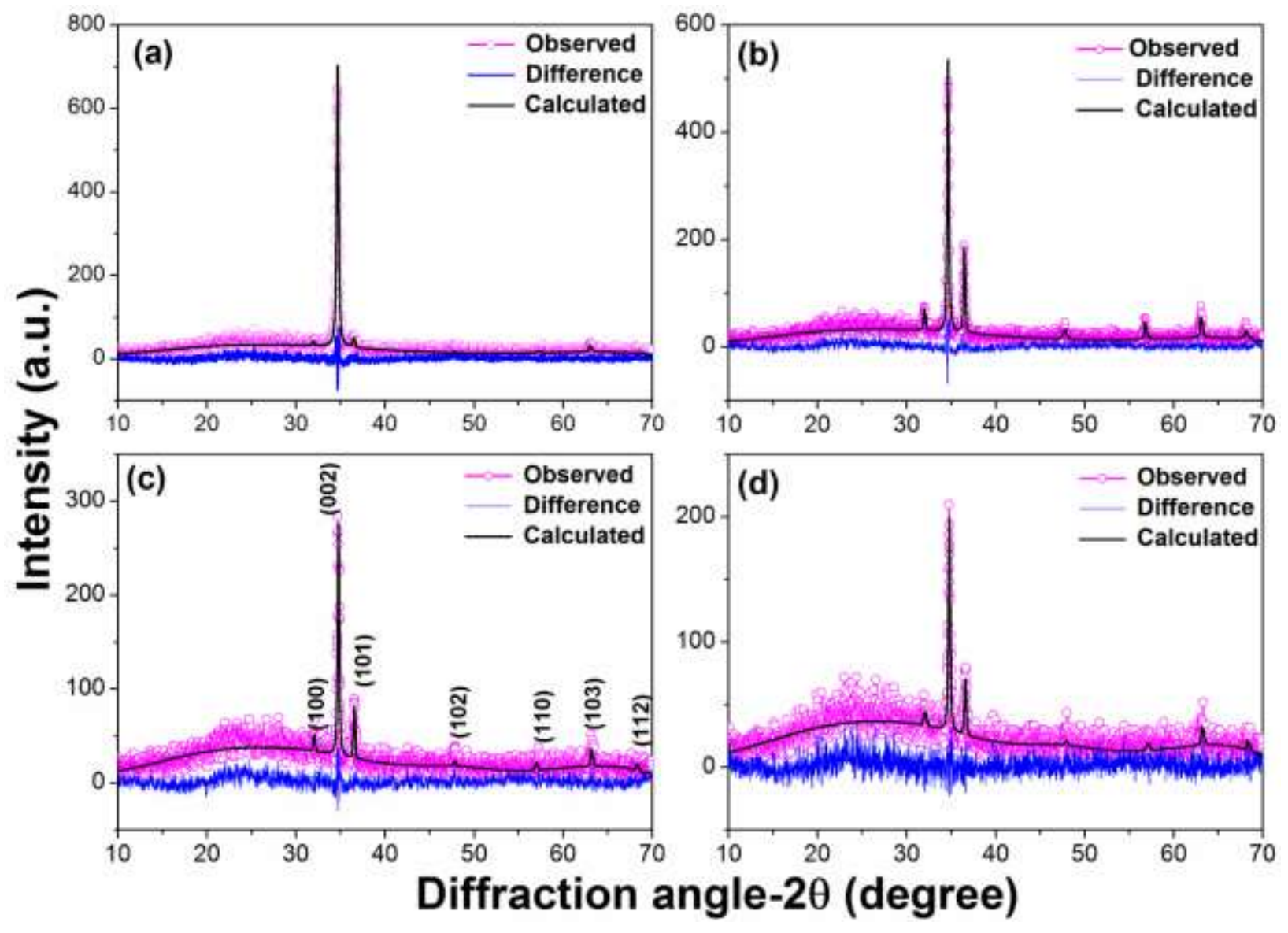

Fig.1 

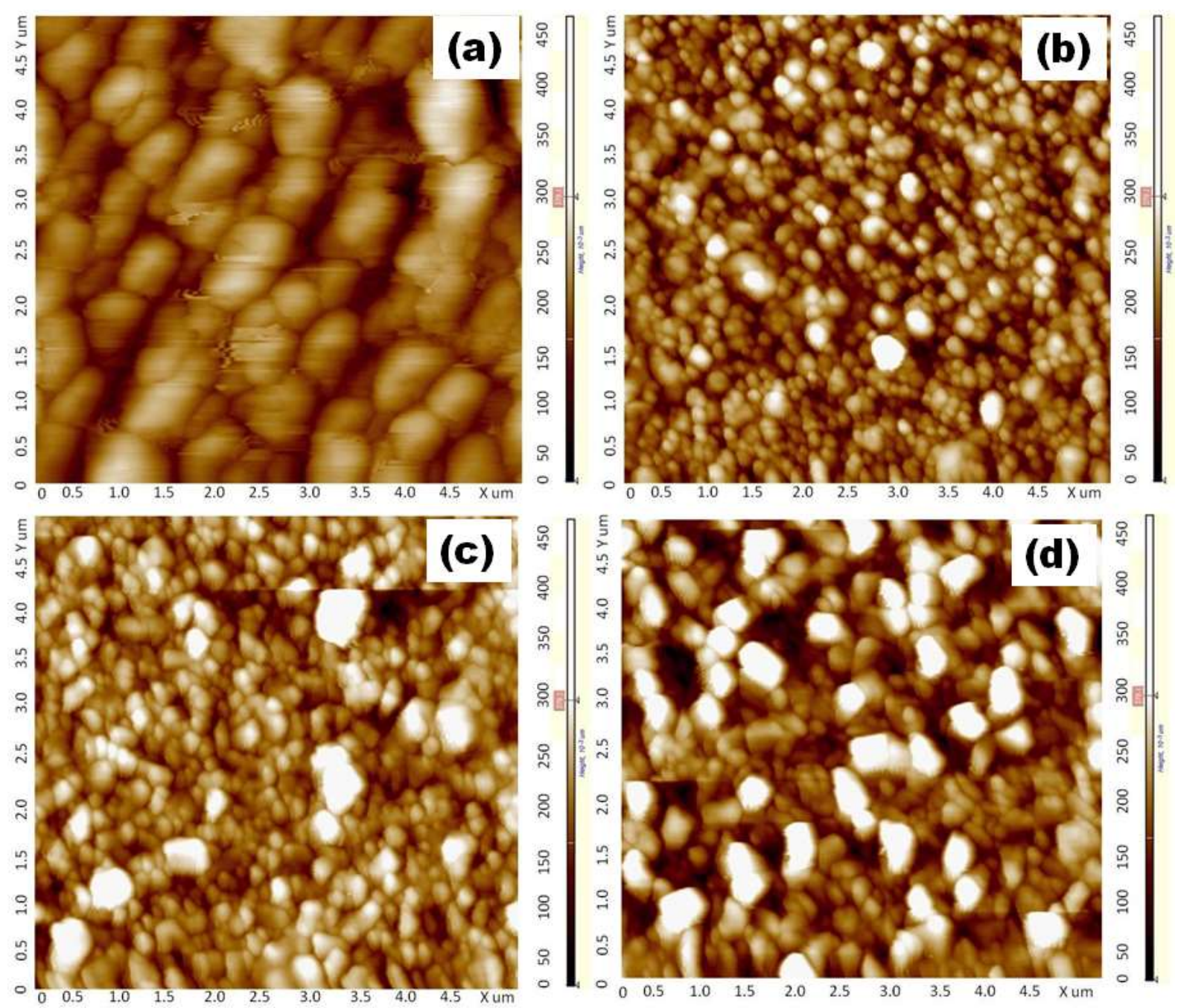

Fig.2 

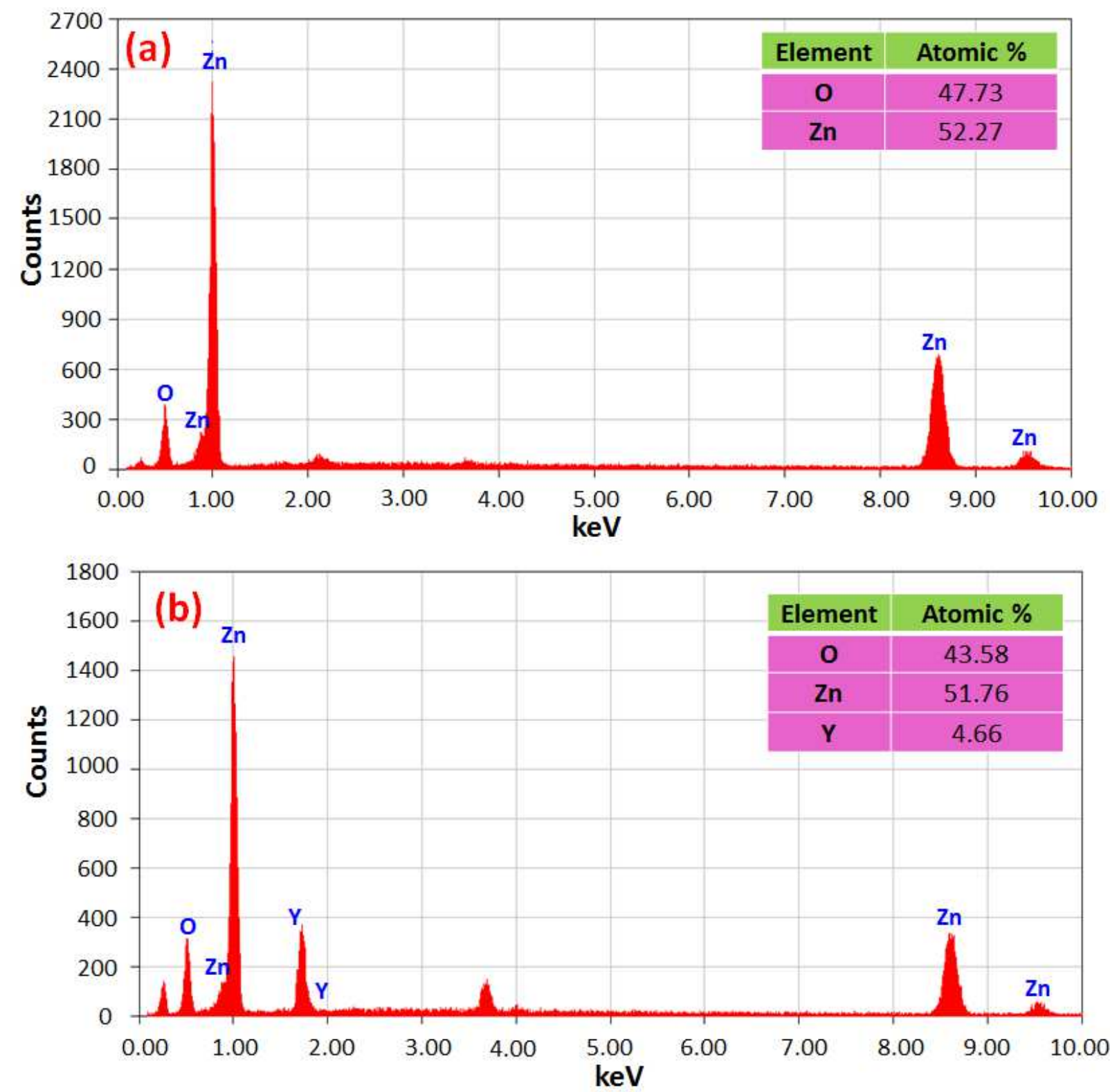

Fig.3 


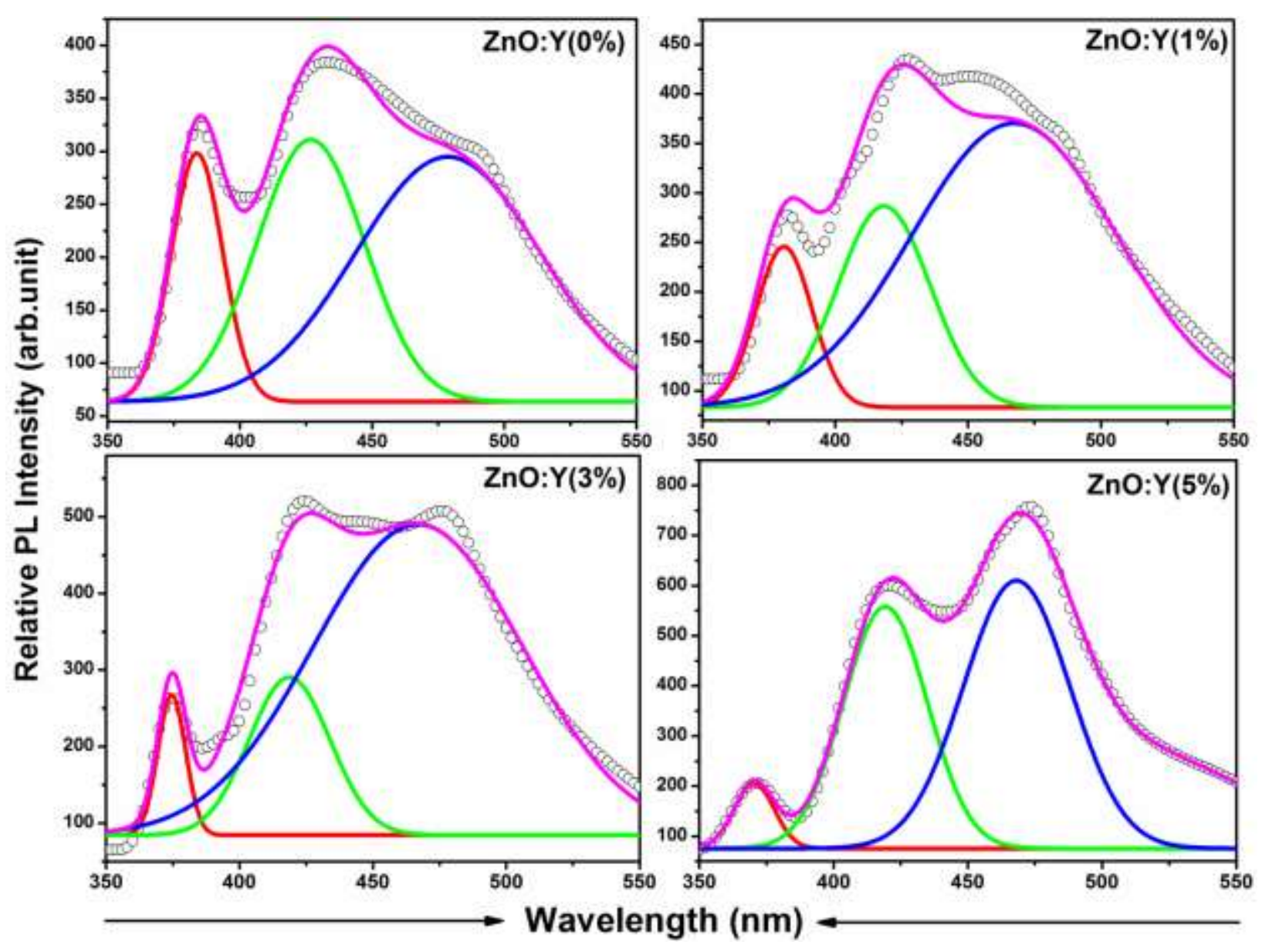

Fig.4 


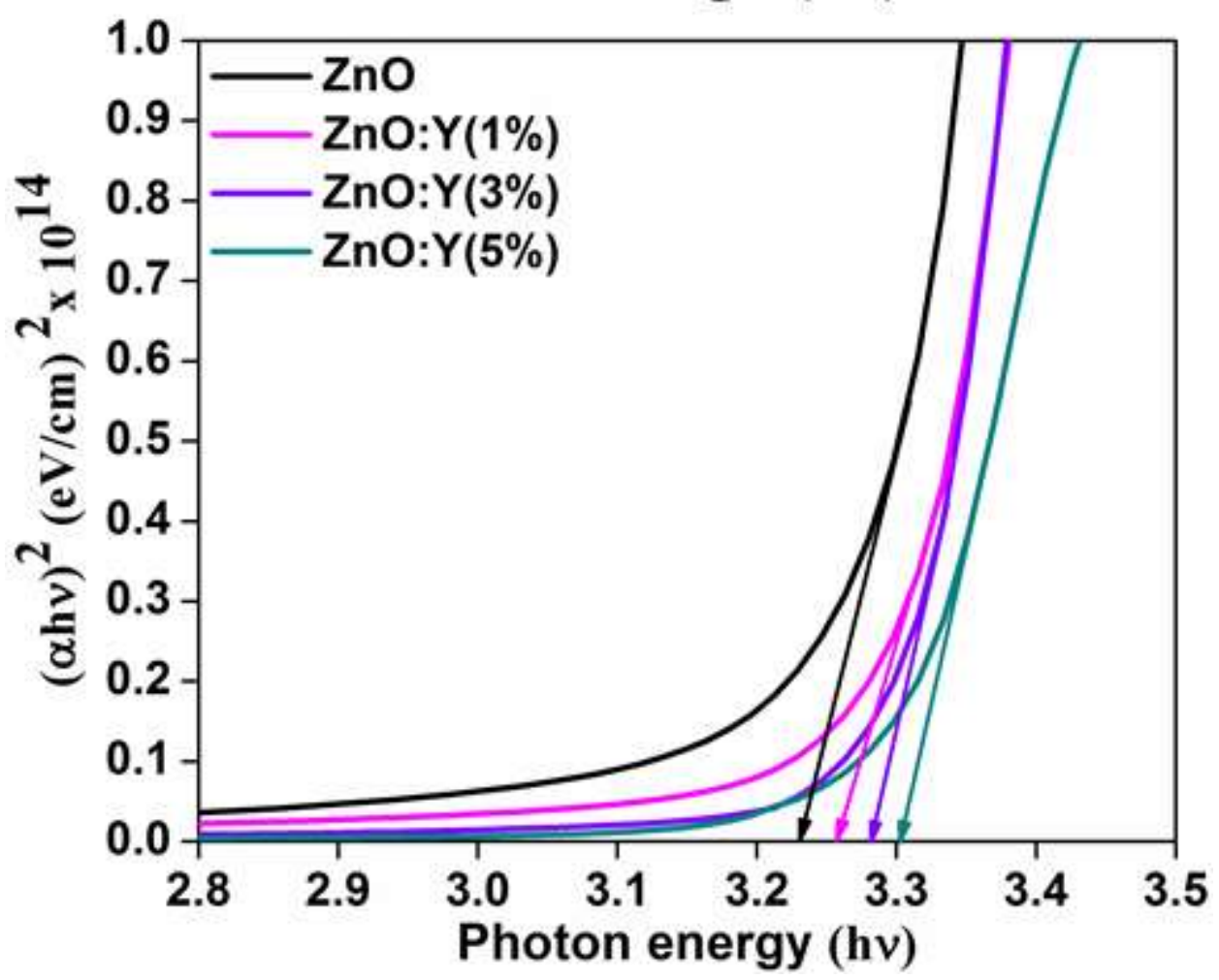

Fig.5 


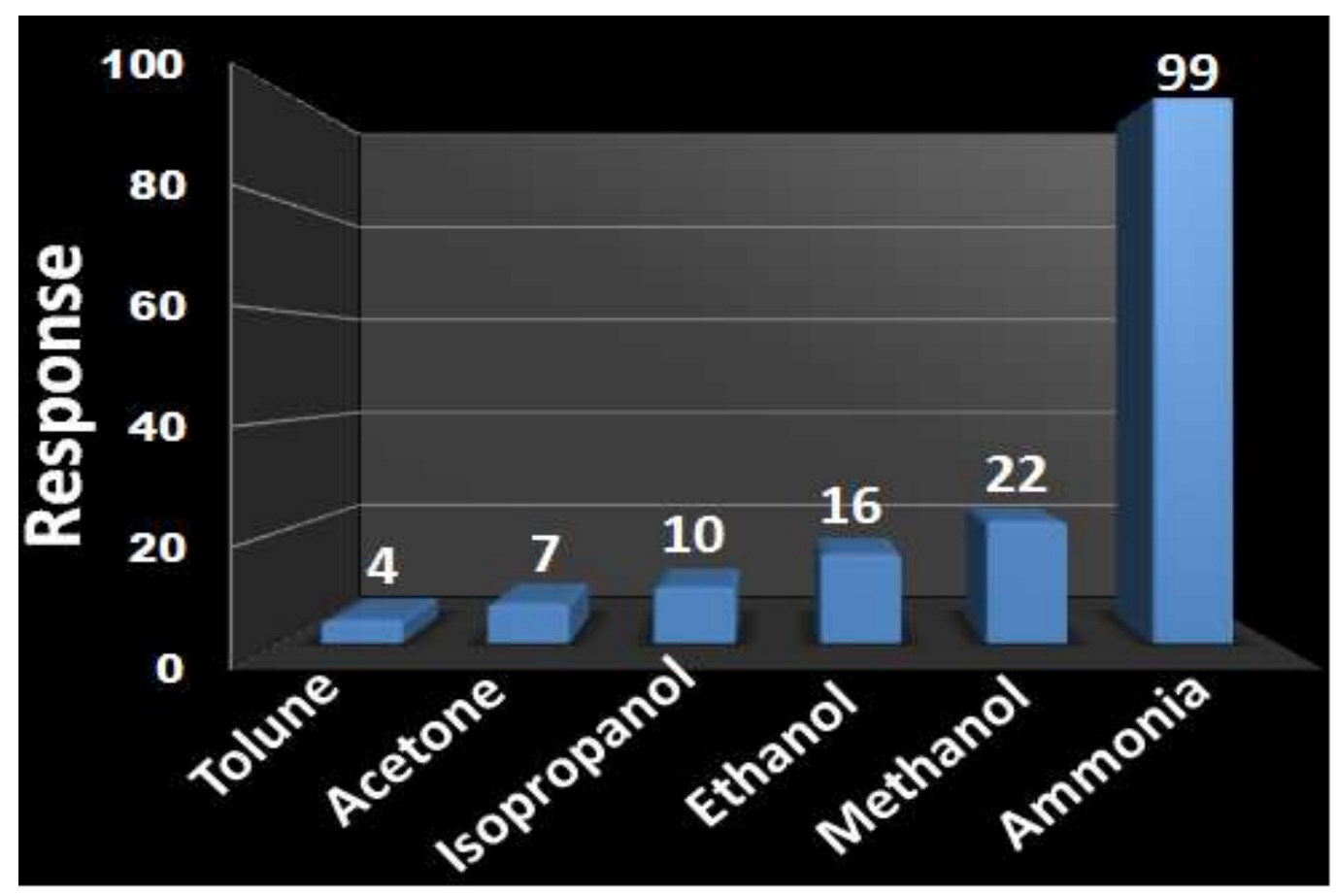

Fig.6 

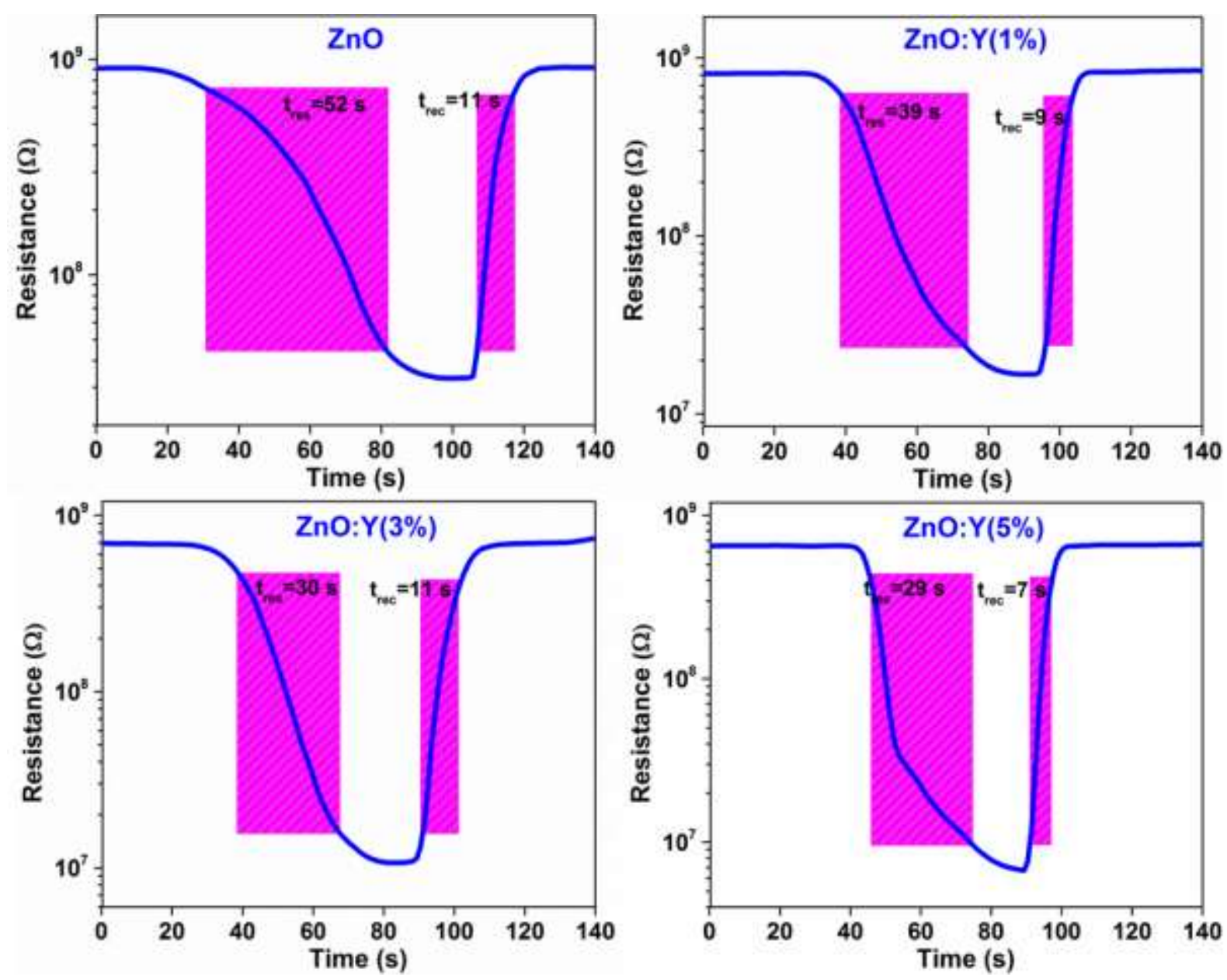

Fig. 7 


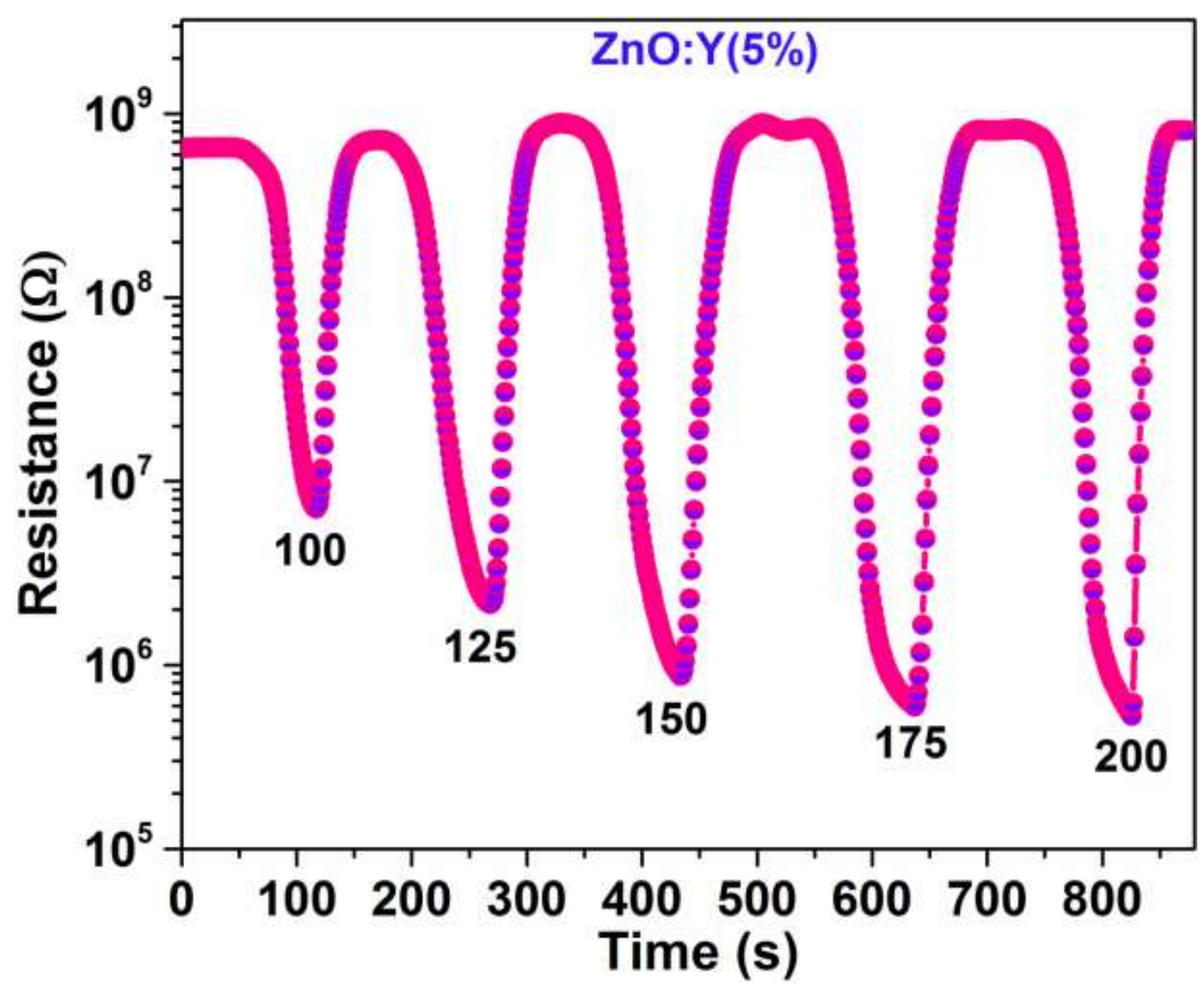

Fig.8 


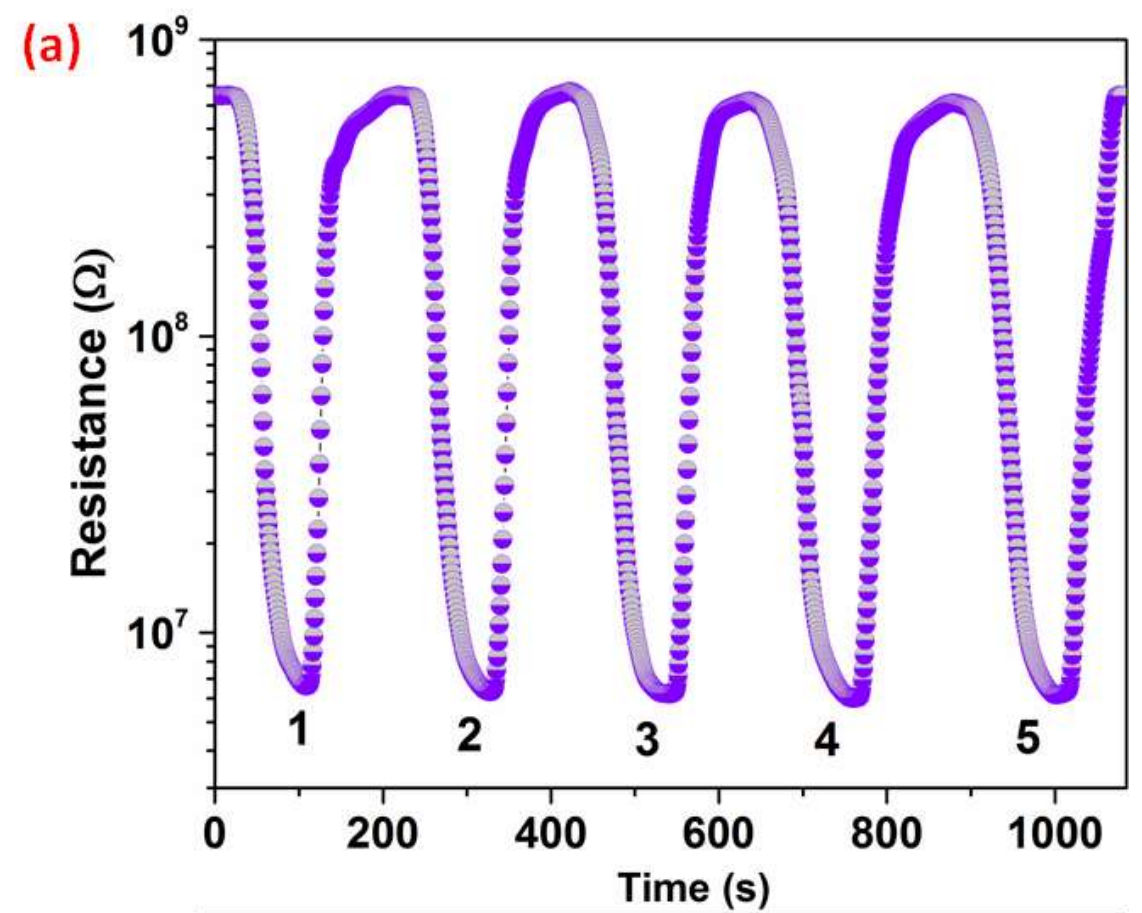

(b)

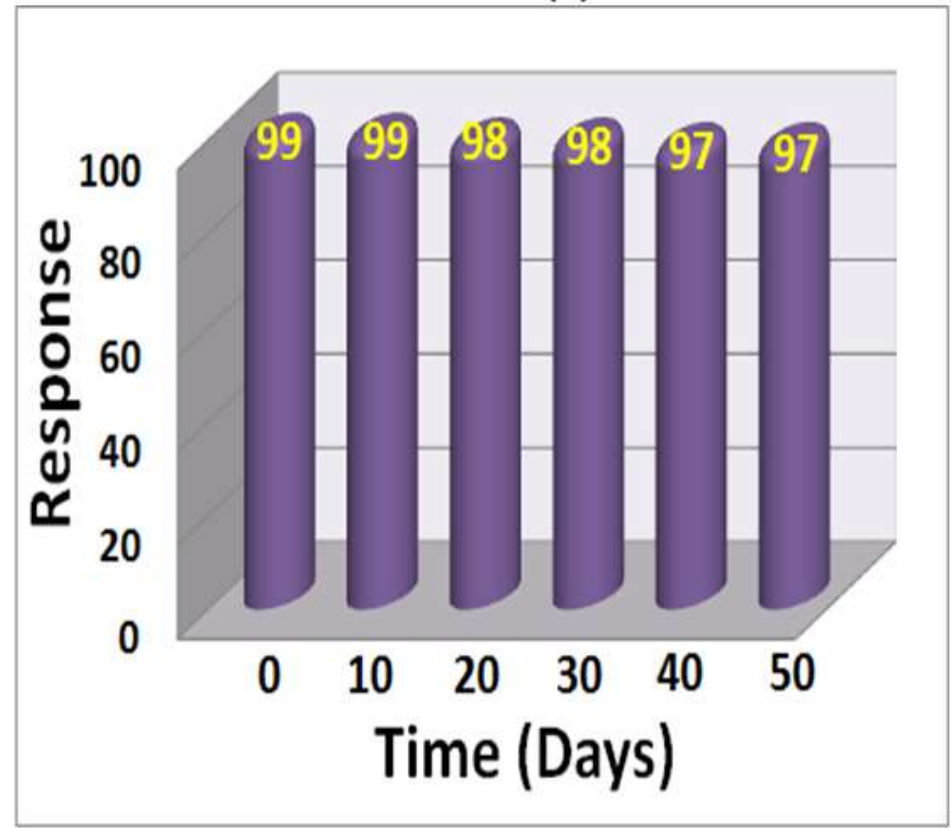

Fig.9 $a$ and $b$ 


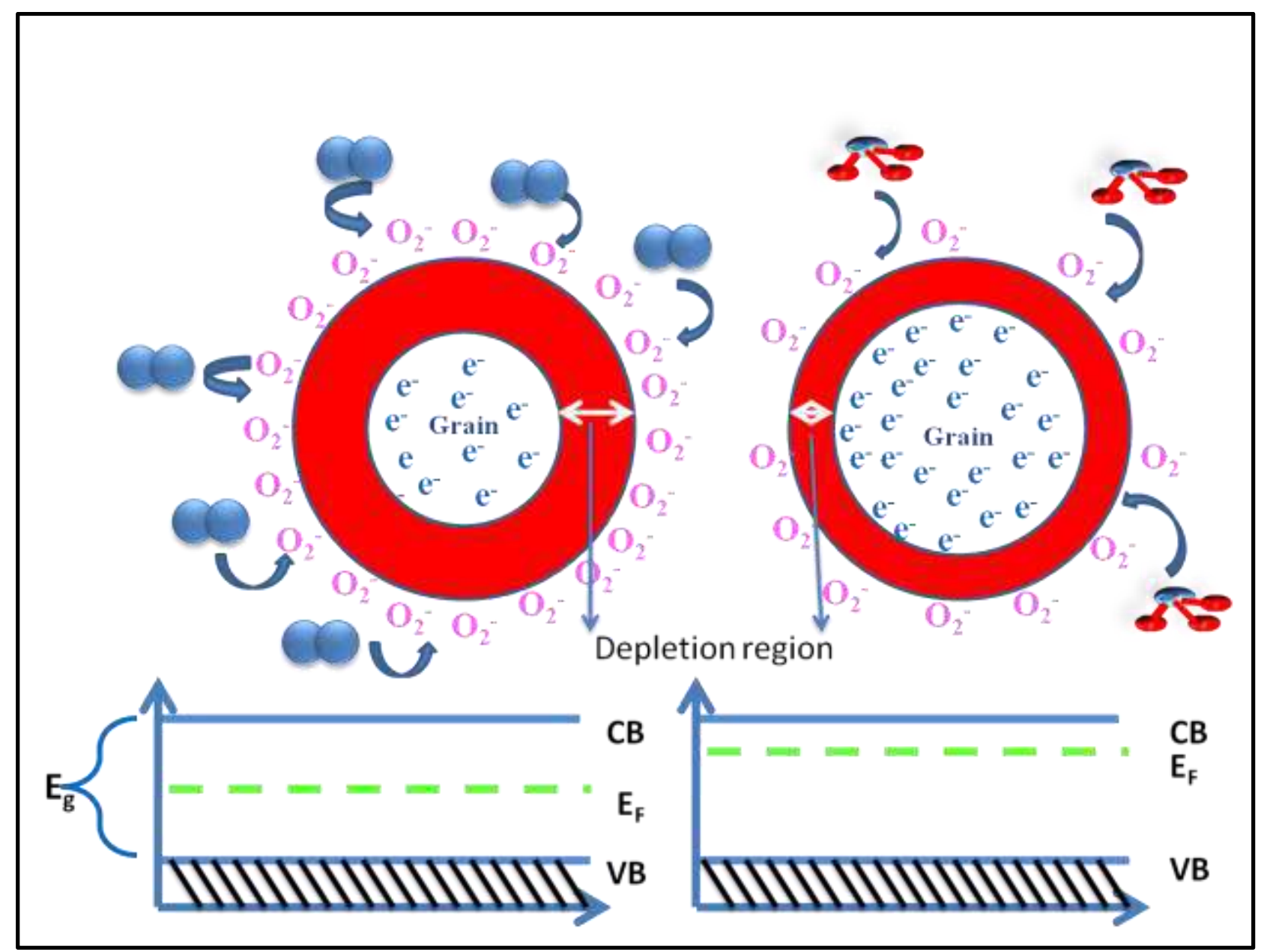

$\mathrm{O}_{2}$ Molecule $\quad \mathrm{S} 5 \mathrm{NH}_{3}$ (Reducing gas)

$\mathrm{O}_{2}^{-}$Adsorbed oxygen e-Conduction band electrons

CB-Conduction band VB-Valence band $\mathbf{E}_{F}$ - Fermi energy

Fig.10 
Table 1

\begin{tabular}{|c|c|c|c|c|c|}
\hline \multirow{2}{*}{ Samples } & \multicolumn{2}{|c|}{ Lattice parameters } & \multirow{2}{*}{$\begin{array}{c}\text { Crystallite size } \\
\text { D (nm) }\end{array}$} & \multirow{2}{*}{$\begin{array}{c}\text { Dislocation } \\
\text { density } \delta\left(\times 10^{15}\right. \\
\text { lines/m² })\end{array}$} & \multirow{2}{*}{$\begin{array}{c}\text { Film } \\
\text { thickness } \\
(\mathbf{n m})\end{array}$} \\
\hline & $\mathbf{a}(\AA)$ & c $(\AA)$ & & & \\
\hline $\mathrm{ZnO}$ & $3.222(5)$ & $5.231(9)$ & 32 & 0.976 & 350 \\
\hline $\mathrm{ZnO}: \mathrm{Y}(1 \%)$ & $3.185(2)$ & $5.173(8)$ & 30 & 1.111 & 340 \\
\hline $\mathrm{ZnO}: \mathrm{Y}(3 \%)$ & $3.186(13)$ & $5.155(5)$ & 29 & 1.189 & 330 \\
\hline $\mathrm{ZnO}: \mathrm{Y}(5 \%)$ & $3.179(2)$ & $5.136(9)$ & 26 & 1.479 & 320 \\
\hline
\end{tabular}

Table 2 


\begin{tabular}{|c|c|c|c|c|c|c|c|}
\hline Material & Method & $\begin{array}{c}\text { Sensing } \\
\text { Temperature } \\
\end{array}$ & $\begin{array}{l}\text { Concentration } \\
(\mathbf{p p m})\end{array}$ & $\begin{array}{l}\text { Response } \\
\text { (S) }\end{array}$ & $\begin{array}{c}\text { Response } \\
\text { time(s) }\end{array}$ & $\begin{array}{c}\text { Recovery } \\
\text { time(s) }\end{array}$ & Ref. \\
\hline $\begin{array}{l}\text { Sr doped } \\
\mathrm{ZnO}\end{array}$ & SILAR & RT & 100 & - & 22 & 6 & [34] \\
\hline$\beta-\mathrm{Ga}_{2} \mathrm{O}_{3}$ & $\begin{array}{c}\text { Spray } \\
\text { pyrolysis }\end{array}$ & RT & $0.5-50$ & $\begin{array}{c}19- \\
33,250\end{array}$ & 40 & 18 & [42] \\
\hline $\begin{array}{l}\mathrm{P}_{2} \mathrm{O}_{5} \\
\text { catalyzed } \\
\text { triazine } \\
\text { frameworks }\end{array}$ & - & RT & 50 & $3.3 \%$ & 54 & 200 & [43] \\
\hline $\begin{array}{c}\text { CdS } \\
\text { decorated } \\
\text { PANI }\end{array}$ & $\begin{array}{l}\text { Chemical co- } \\
\text { dispersion }\end{array}$ & RT & $20-100$ & 250 & 58 & 104 & [46] \\
\hline $\mathrm{SnO}_{2} / \mathrm{MoS}_{2}$ & Hydrothermal & RT & 50 & 2080.36 & 23 & 1.6 & [47] \\
\hline $\mathrm{NiO} / \mathrm{CuO}$ & $\begin{array}{l}\text { Electroless } \\
\text { deposition }\end{array}$ & RT & 20 & - & 72.5 & 35 & [48] \\
\hline $\begin{array}{l}\mathrm{Pd} / \mathrm{SnO}_{2} / \mathrm{RG} \\
\mathrm{O}\end{array}$ & One pot route & RT & 100 & 19.6 & 420 & 3000 & [49] \\
\hline $\begin{array}{l}\text { Yttrium } \\
\text { doped } \mathrm{ZnO}\end{array}$ & $\begin{array}{l}\text { Nebulizer } \\
\text { spray } \\
\text { Pyrolysis }\end{array}$ & RT & 100 & 99 & 29 & 7 & $\begin{array}{l}\text { Present } \\
\text { work }\end{array}$ \\
\hline
\end{tabular}


Figures
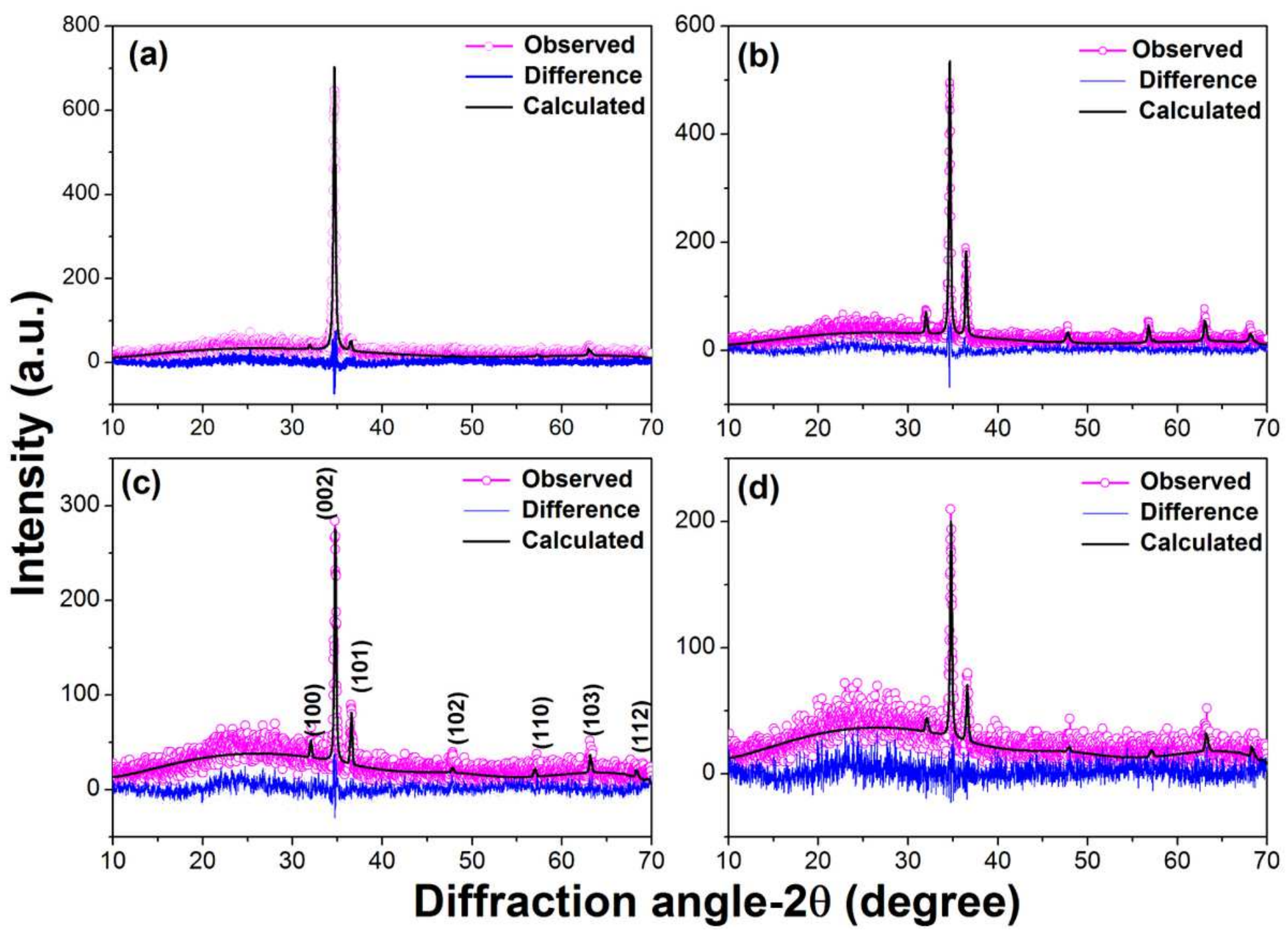

Figure 1

X-ray diffraction patterns of $\mathrm{ZnO}$ and $\mathrm{ZnO}: \mathrm{Y}$ thin films 

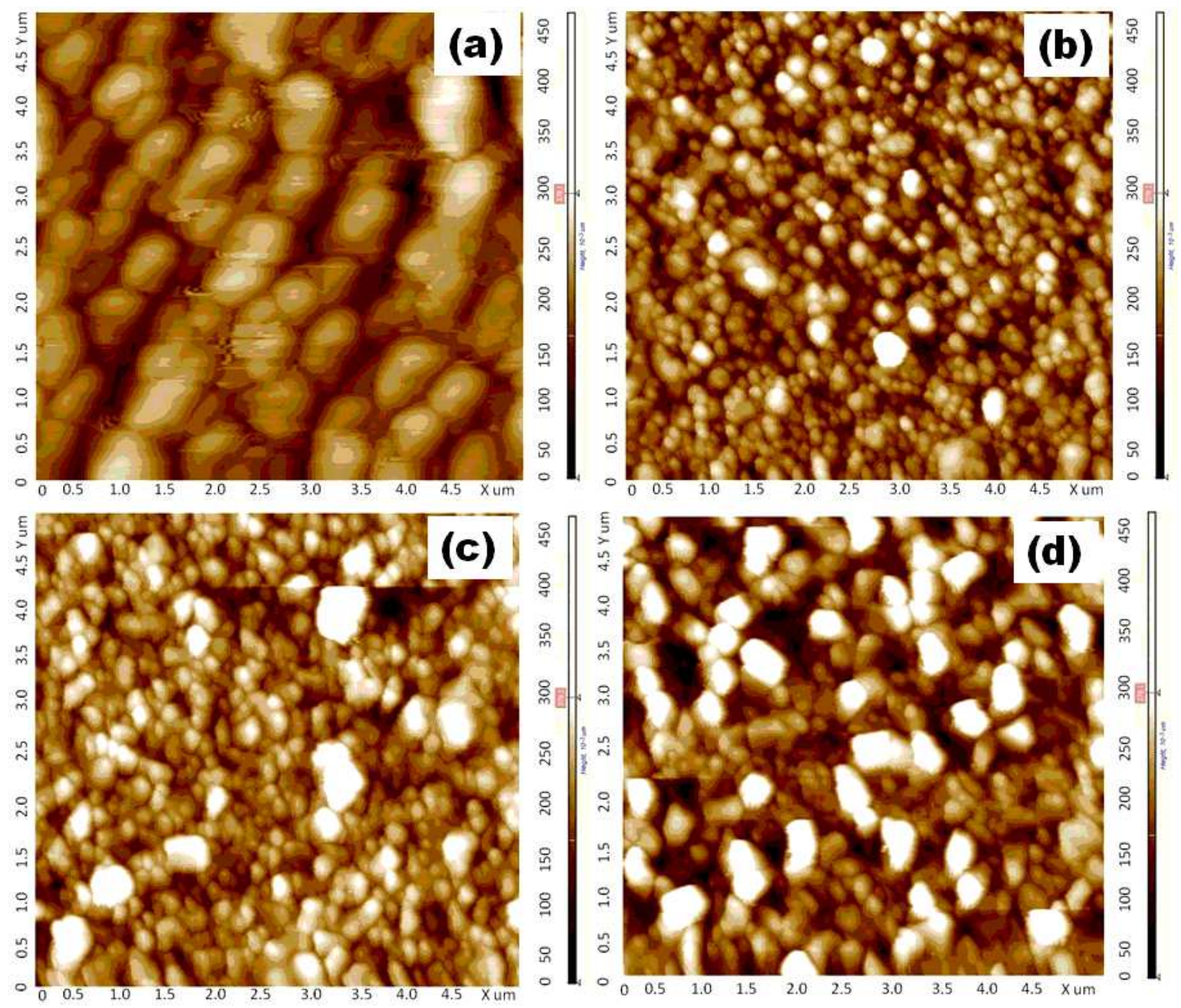

Figure 2

AFM images of ZnO:Y thin films with different $Y$ loading levels a) 0 b) 1 c) 3 and d) $5 w t \%$ 

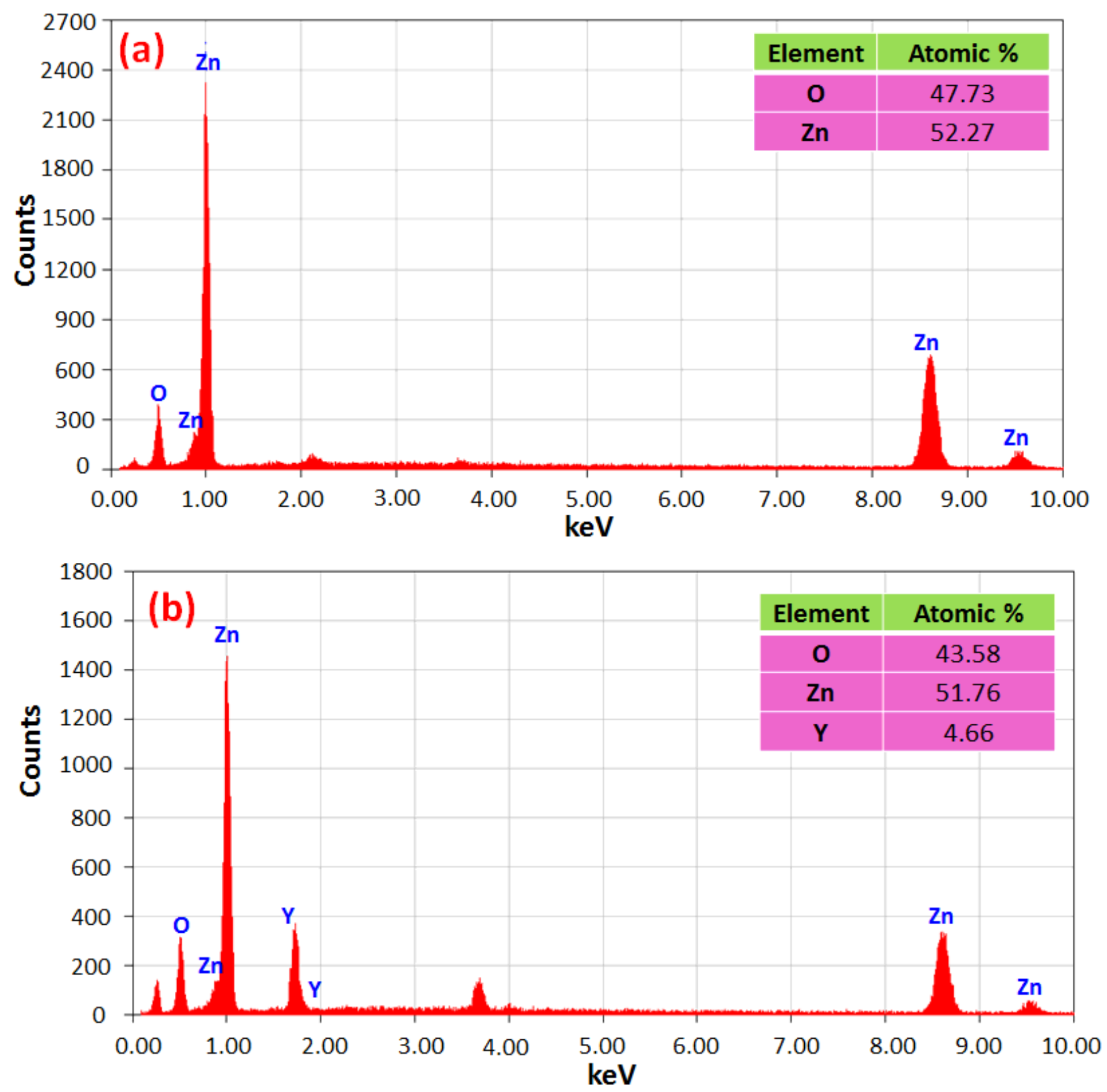

Figure 3

$(a, b)$ EDX spectra of $\mathrm{ZnO}$ and $\mathrm{ZnO}: \mathrm{Tb}(5 \mathrm{wt} \%)$ thin films 


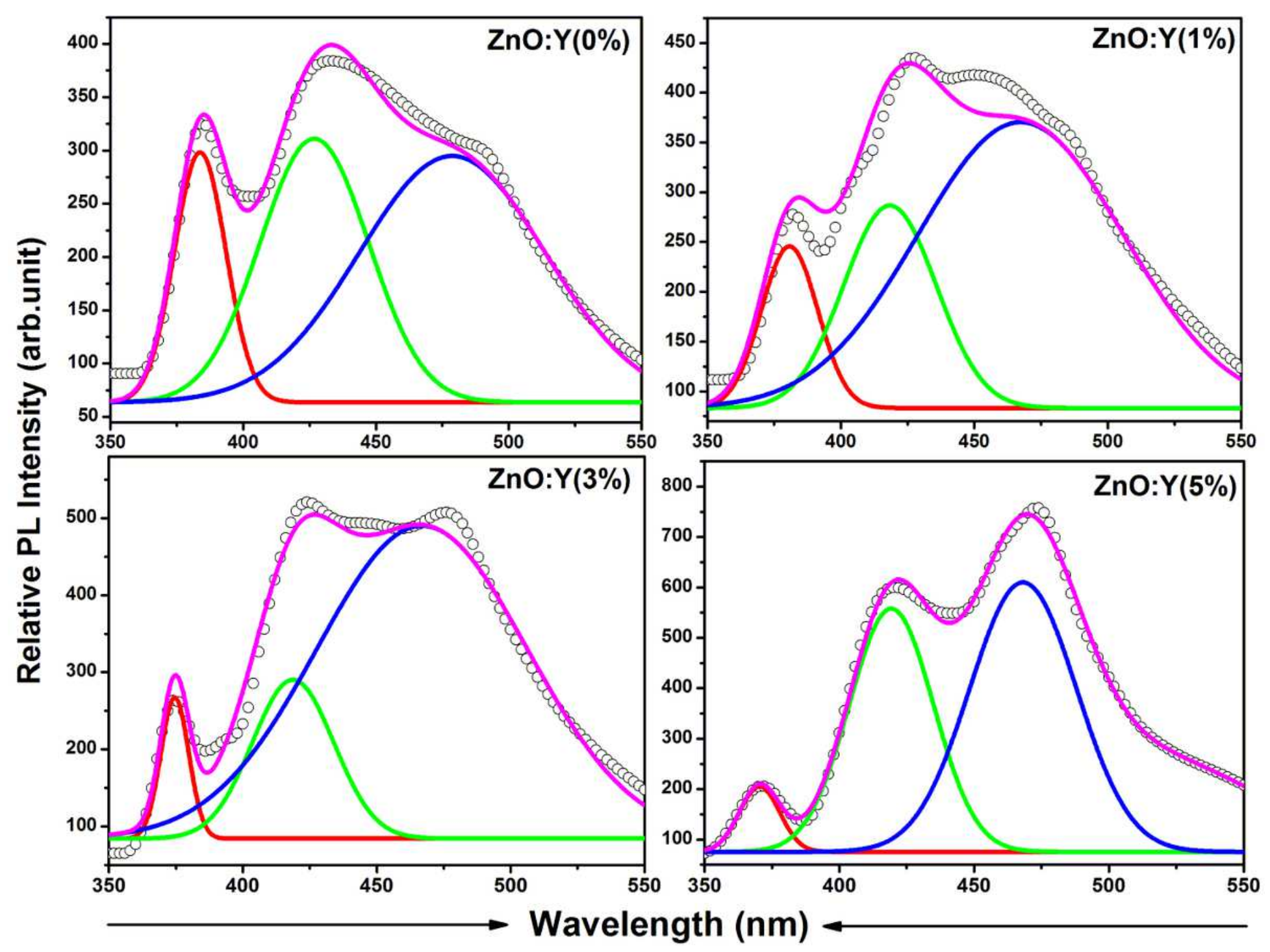

Figure 4

Photoluminescence spectra of $\mathrm{ZnO}$ and $\mathrm{Y}$ doped $\mathrm{ZnO}$ thin films 


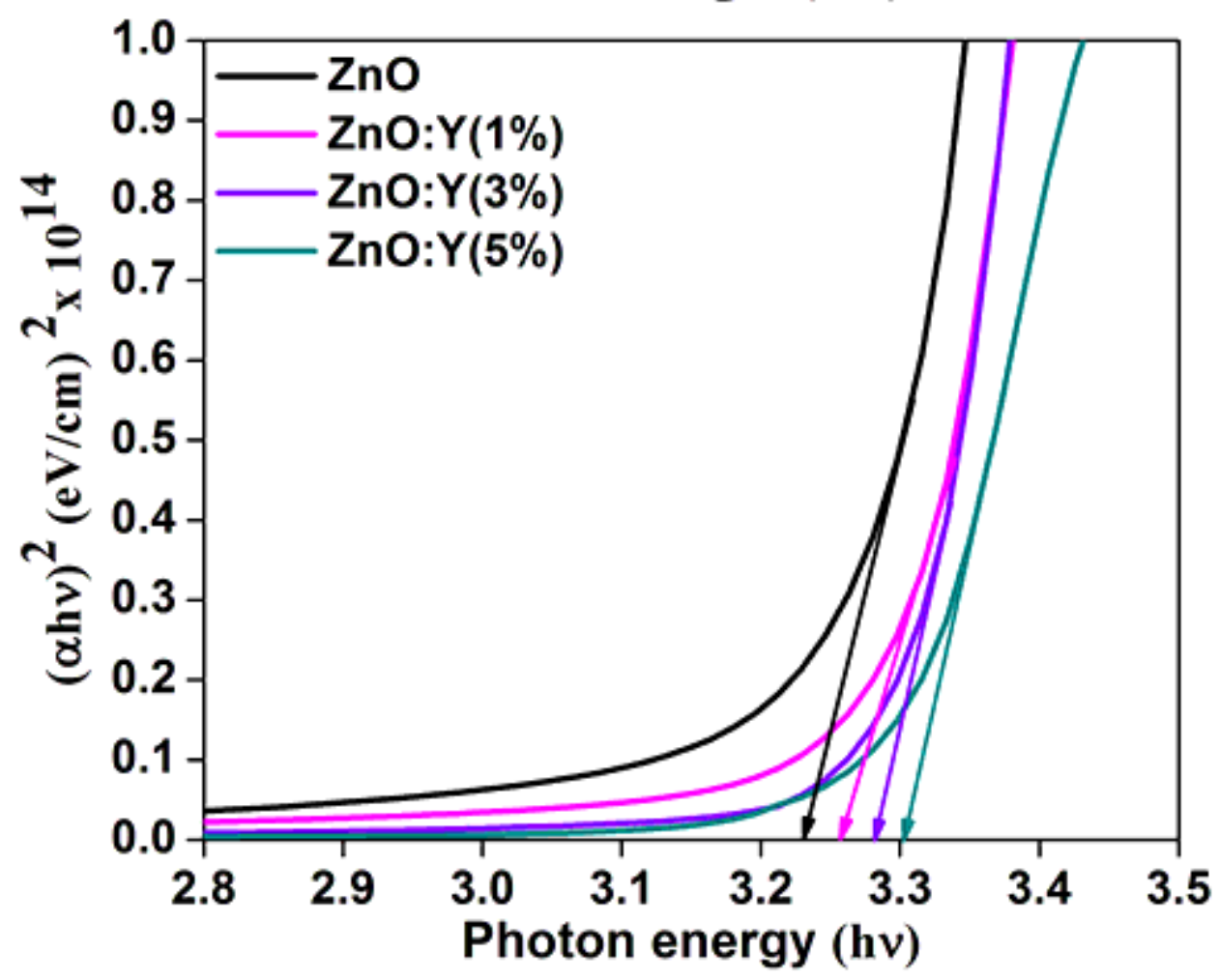

Figure 5

Tauc's plot of ZnO and ZnO:Y (1, 3 and $5 \mathrm{wt} \%)$ thin films to measure the bandgap

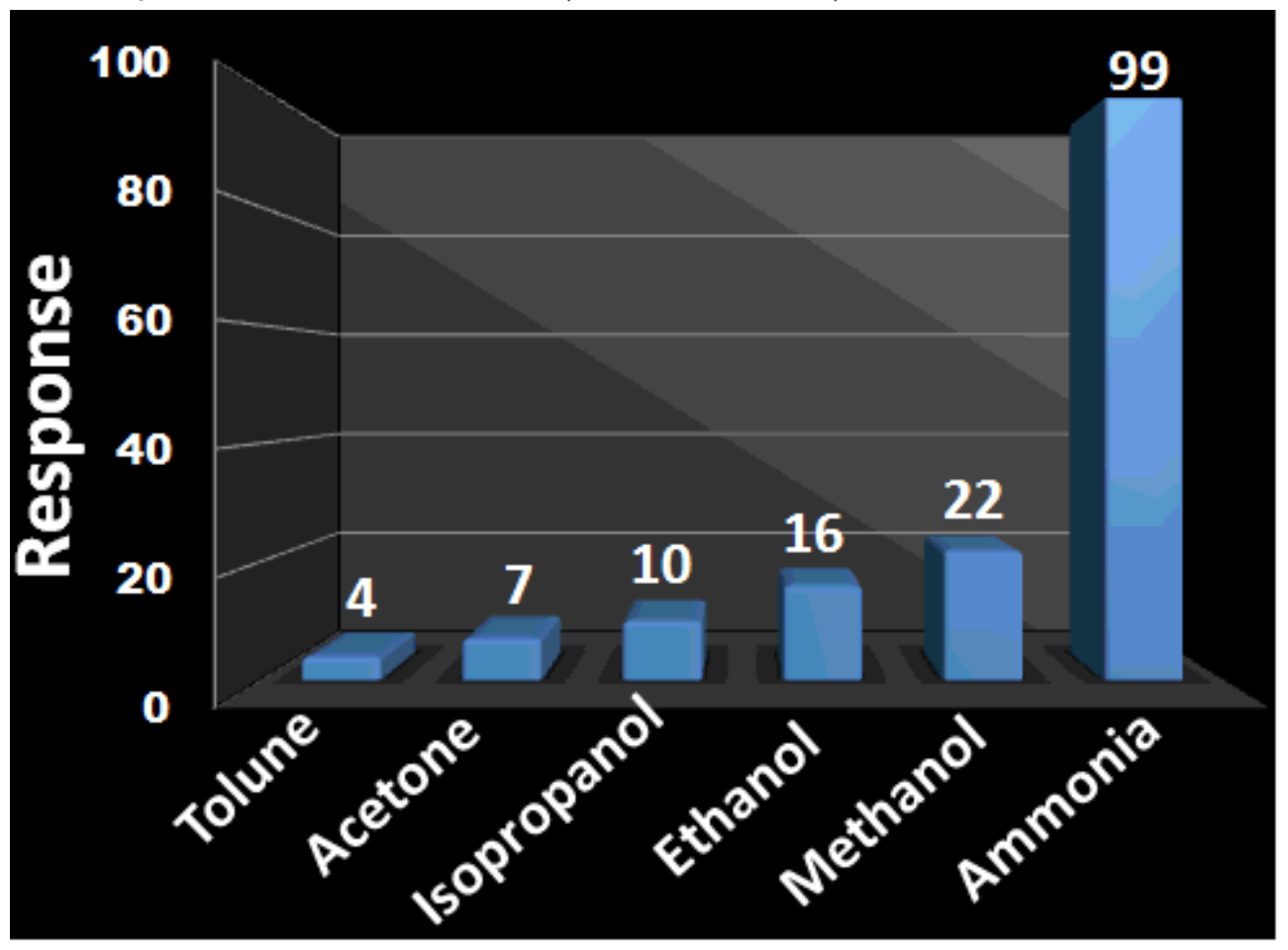

Figure 6

Selectivity of ZnO:Y-5wt\% thin film towards various test vapours 

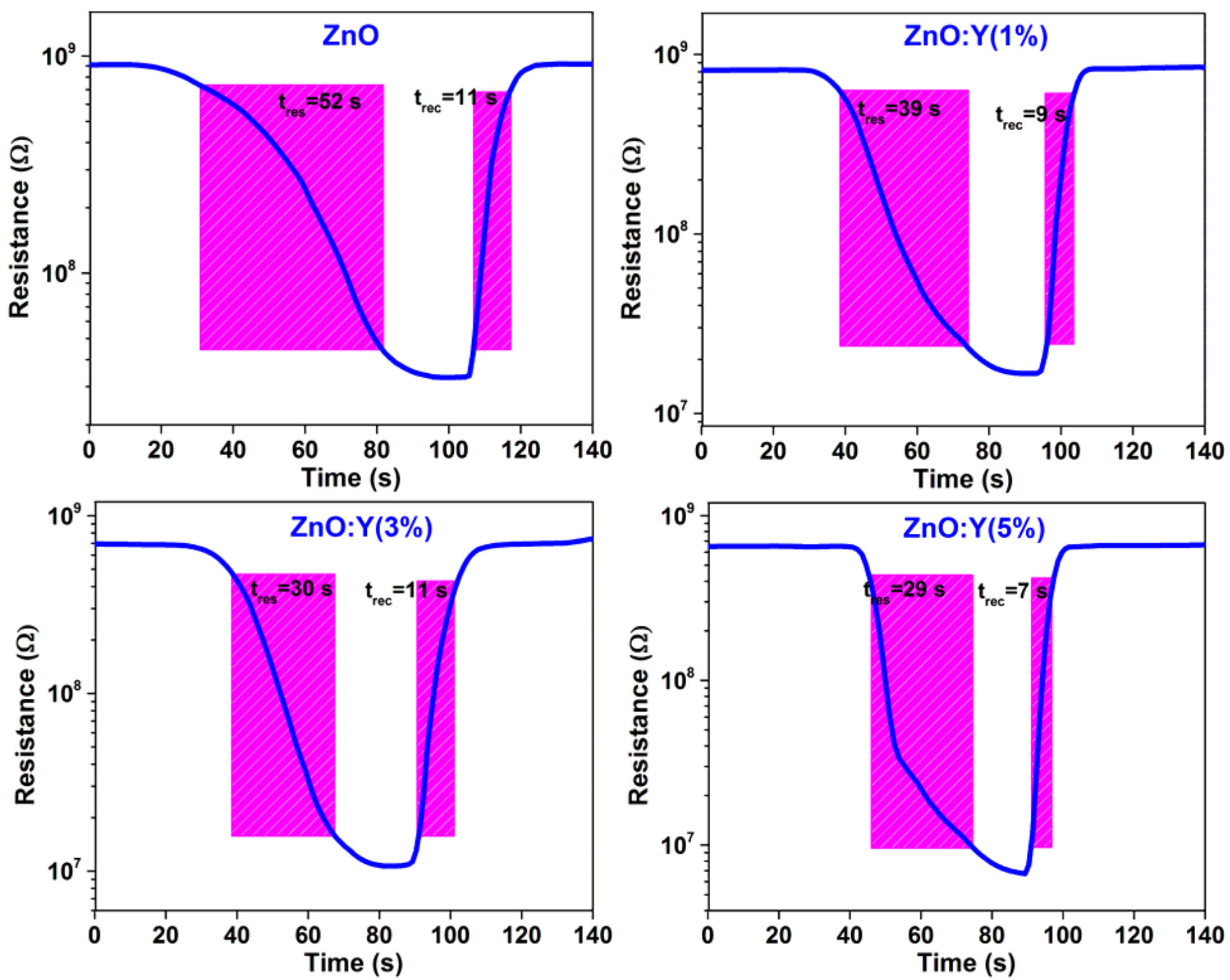

Figure 7

Response and recovery curves of $\mathrm{ZnO}: \mathrm{Y}(0,1,3$ and $5 \mathrm{wt} \%)$ thin films towards $100 \mathrm{ppm}$ of $\mathrm{NH} 3$ at room temperature 


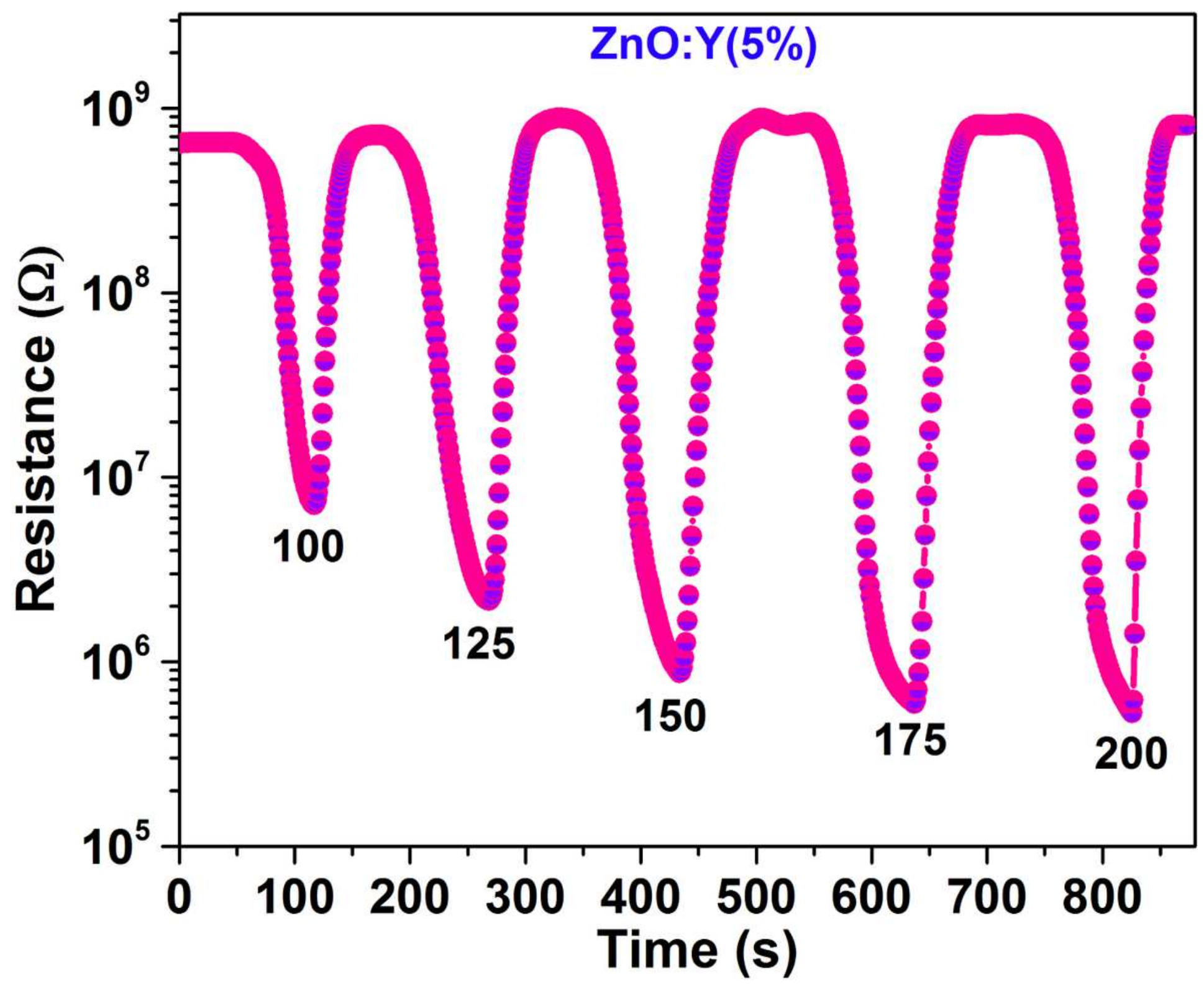

Figure 8

Response and recovery curves of $5 \mathrm{wt} \%$ yttrium doped $\mathrm{ZnO}$ thin film towards various concentrations of $\mathrm{NH} 3$ 


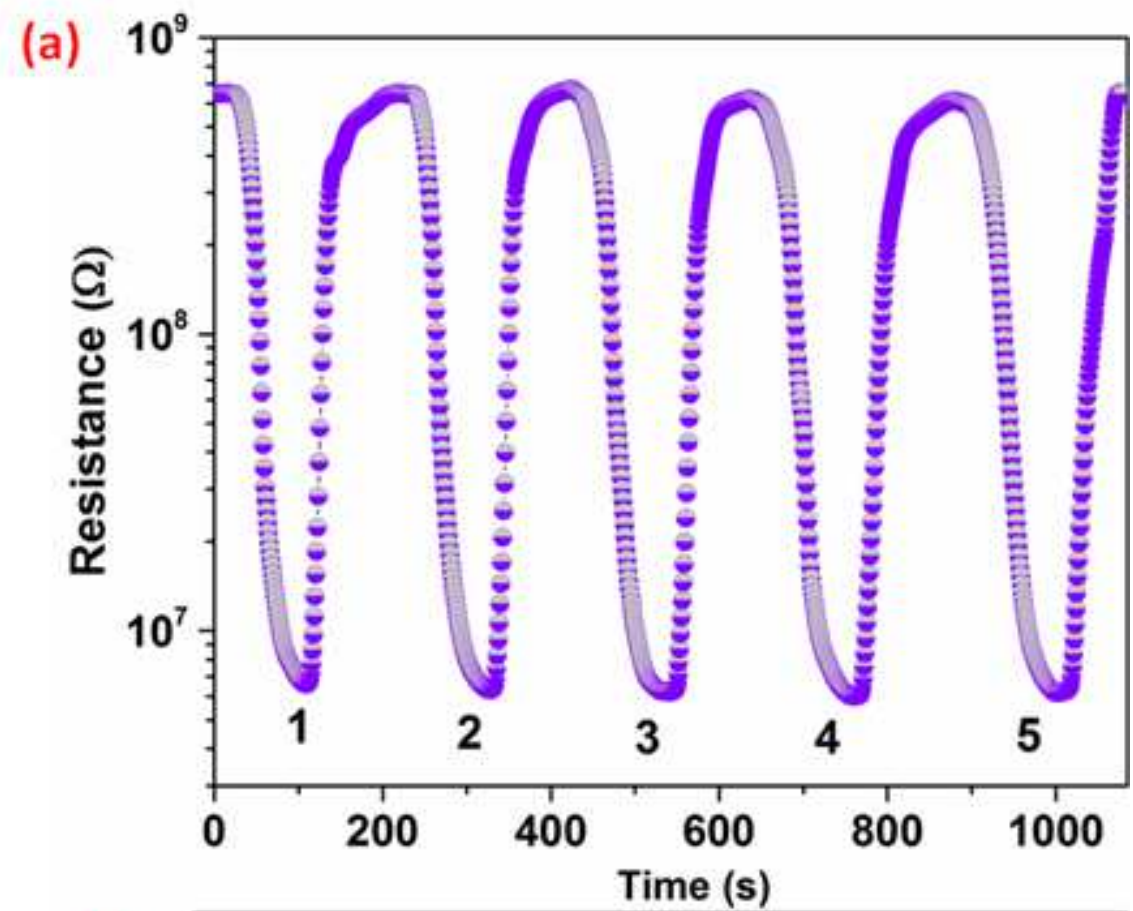

(b)

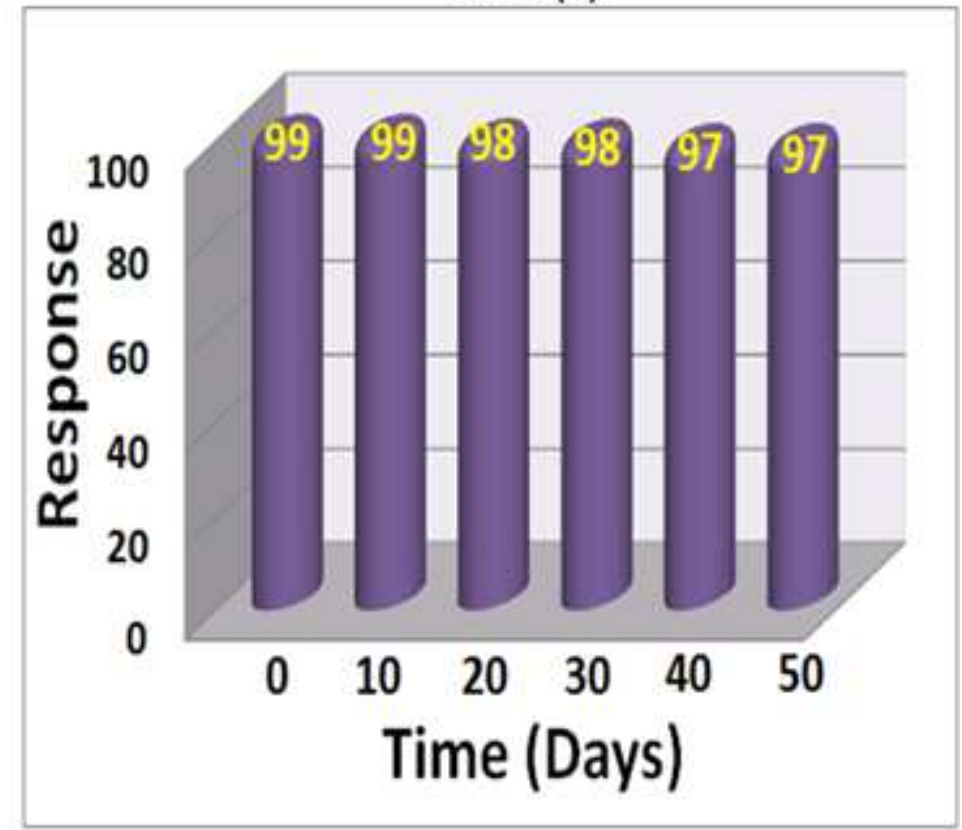

Figure 9

a) Repeatability curve of $5 \mathrm{wt} \%$ yttrium doped $\mathrm{ZnO}$ thin films b) Stability curve of $\mathrm{ZnO}: \mathrm{Y}(0,1,3$ and 5 $w t \%)$ thin films over 50 days 


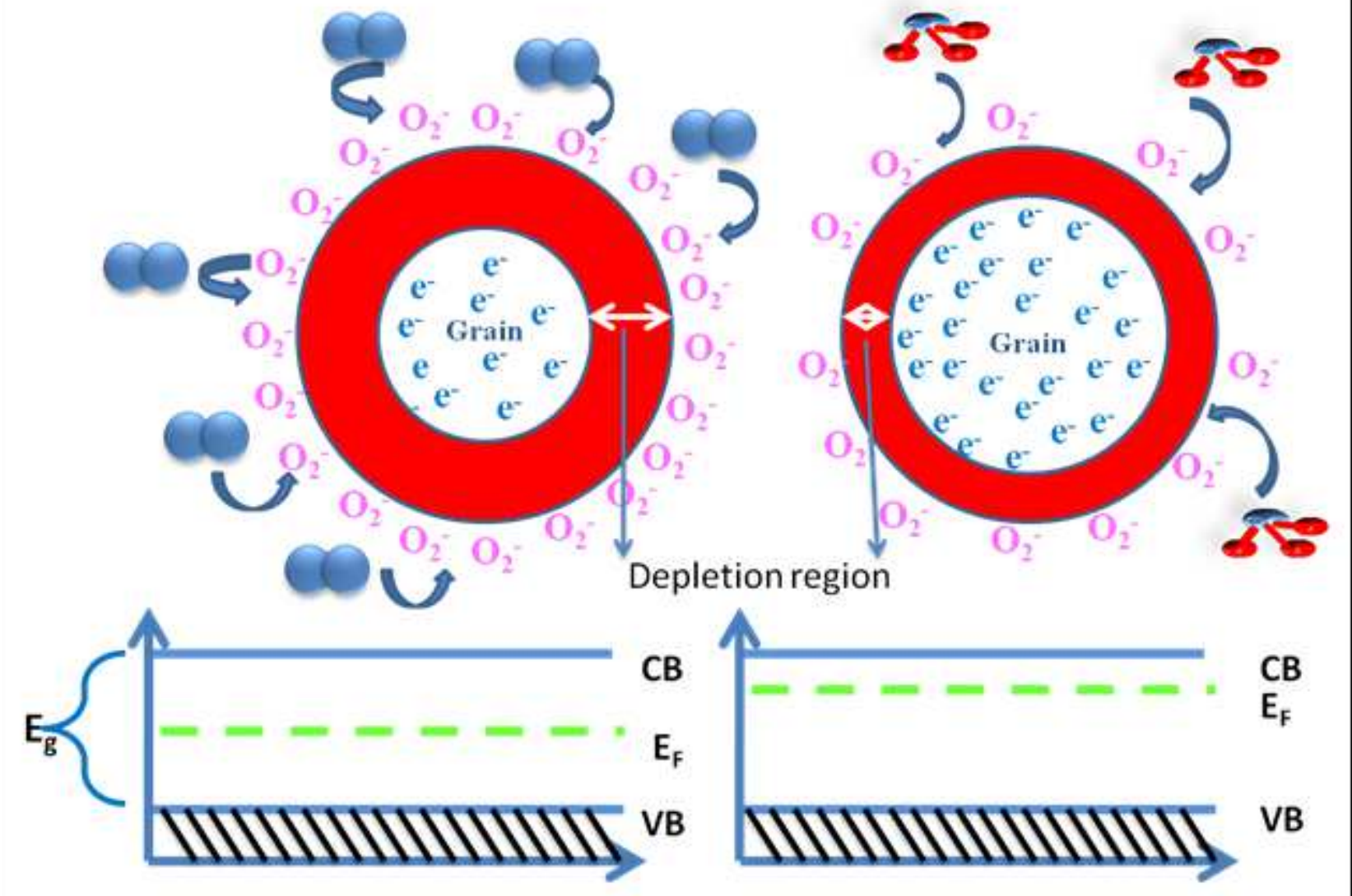

$\mathrm{O}_{2}$ Molecule $25 \mathrm{NH}_{3}$ (Reducing gas)

$\mathrm{O}_{2}^{-}$Adsorbed oxygen e- Conduction band electrons

CB-Conduction band VB-Valence band $\mathrm{E}_{\mathrm{F}}$-Fermi energy

Figure 10

Sensing mechanism of $\mathrm{ZnO}: \mathrm{Y}$ thin film

\section{Supplementary Files}

This is a list of supplementary files associated with this preprint. Click to download.

- Onlinefloatimage10.png 